\title{
Health and economic impact of rotavirus vaccination in GAVI-eligible countries
}

\author{
Sun-Young Kim¹,2, Steve Sweet ${ }^{1}$, David Slichter ${ }^{1,2}$ and Sue J Goldie ${ }^{1,2}$
}

\begin{abstract}
Background: Rotavirus infection is responsible for about 500,000 deaths annually, and the disease burden is disproportionately borne by children in low-income countries. Recently the World Health Organization (WHO) has released a global recommendation that all countries include infant rotavirus vaccination in their national immunization programs. Our objective was to provide information on the expected health, economic and financial consequences of rotavirus vaccines in the $72 \mathrm{GAVI}$ support-eligible countries.
\end{abstract}

Methods: We synthesized population-level data from various sources (primarily from global-level databases) for the 72 countries eligible for the support by the GAVI Alliance (GAVI-eligible countries) in order to estimate the health and economic impact associated with rotavirus vaccination programs. The primary outcome measure was incremental cost (in 2005 international dollars [I\$]) per disability-adjusted life year (DALY) averted. We also projected the expected reduction in rotavirus disease burden and financial resources required associated with a variety of scale-up scenarios.

Results: Under the base-case assumptions (70\% coverage), vaccinating one single birth cohort would prevent about $55 \%$ of rotavirus associated deaths in the $72 \mathrm{GAVI}$-eligible countries. Assuming 1 \$25 per vaccinated child ( $\$ 5$ per dose), the number of countries with the incremental cost per DALY averted less than I\$200 was 47. Using the WHO's costeffectiveness threshold based on per capita GDP, the vaccines were considered cost-effective in 68 of the 72 countries ( 94\%). A 10-year routine rotavirus vaccination would prevent 0.9-2.8 million rotavirus associated deaths among children under age 5 in the poorest parts of the world, depending on vaccine scale-up scenarios. Over the same intervention period, rotavirus vaccination programs would also prevent 4.5-13.3 million estimated cases of hospitalization and 41-107 million cases of outpatient clinic visits in the same population.

Conclusions: Our findings suggest that rotavirus vaccination would be considered a worthwhile investment for improving general development as well as childhood health level in most low-income countries, with a favorable costeffectiveness profile even under a vaccine price ( $\$ 1.5-\$ 5.0$ per dose) higher than those of traditional childhood vaccines.

\section{Background}

While childhood diarrhea can be caused by multiple pathogens, including both bacteria and viruses, rotavirus is the most common cause of severe diarrhea leading to hospitalization or disease-specific death among children under 5 years of age $[1,2]$. Responsible for more than 2 million hospitalizations and 500,000 deaths annually (as of 2004), disease mortality is disproportionately borne by children in low-income countries in Africa and Asia [3]. Since almost all children are infected by age 5 , and

* Correspondence: sykim@hsph.harvard.edu

${ }^{1}$ Center for Health Decision Science, Department of Health Policy and Management, Harvard School of Public Health, Boston MA, USA Full list of author information is available at the end of the article improved hygiene, water and sanitation measures have had little impact on disease burden, vaccination is considered among the most promising of strategies to prevent mortality [2].

Rotavirus has diverse genotypes that vary geographically and over time [4-6], with clinical manifestations of infection depending heavily on the patient's age [7]. Rotavirus is also characterized by frequent reinfection, with developed natural immunity depending on the number of prior infections. In the last 5 years, two new oral, live attenuated rotavirus vaccines, Rotarix (GlaxoSmithKline) [a two-dose monovalent live attenuated human rotavirus vaccine] and RotaTeq (Merck \& Co., Inc.) [a 
three-dose human-bovine reassortant pentavalent rotavirus vaccine], have been licensed and are now available in many countries $[8,9]$. In 2005, the World Health Organization (WHO) Strategic Advisory Group of Experts (SAGE) on Immunization, recommended the introduction of these vaccines in Europe, the United States, and Latin America, on the basis of results of phase III clinical trials [8]; both vaccines appeared to have partial efficacy of a similar magnitude as that conferred by a single natural infection. However, SAGE initially withheld a global recommendation until clinical trials could show satisfactory efficacy in Africa and Asia [8,9]. Clinical trials of Rotarix (completed in 2008) demonstrated a reduction of rotavirus disease burden in South Africa and Malawi [10]. Based on this newer evidence, in June 2009, SAGE recommended that all countries include infant rotavirus vaccination in their national immunization programs [10].

Especially in light of the Millennium Development Goal (MDG) 4 of child mortality reduction, there has been an effort at the global level to accelerate introduction of rotavirus vaccines in developing countries. However, in addition to the uncertainties about ultimate efficacy in Africa and Asia, as well as uncertainties about the likelihood of uptake, the current vaccines are costly relative to traditional childhood vaccines. Undoubtedly, the poorest countries will require financial assistance. The GAVI Alliance has promised to provide financial support for rotavirus vaccination programs to developing countries, and the WHO and its partners have established global networks for surveillance of rotavirus, providing valuable data on the burden of severe types of acute rotavirus gastroenteritis [11]. However, given that the countries eligible for support from the GAVI Alliance (GAVI-eligible countries) face numerous challenges, not the least of which is the need to fund other children's health initiatives within constrained budgets, countries are being encouraged to consider the potential health impact, cost-effectiveness, and financial requirements carefully, before choosing to prioritize rotavirus vaccines.

The objective of this analysis is to use population-based data for 72 GAVI-eligible countries and provide information on the expected health, economic, and financial consequences of rotavirus vaccines.

\section{Methods}

\section{Analytic overview}

We synthesized population-level data on demographic structure, country- or region-specific disease burden, medical utilization patterns for treating rotavirus diseases, and costs in order to estimate the health and economic consequences associated with rotavirus vaccination programs in the 72 GAVI-eligible countries. (The data used for our study is openly available upon request.) Model-projected clinical outcomes include intermediate health outcomes (e.g., hospitalizations), deaths averted, years of life saved (YLS), and disabilityadjusted life years (DALYs) averted. The primary outcome measure for the cost-effectiveness analysis was incremental cost (expressed in 2005 international dollars [I\$] adjusted for price differences across countries using purchasing power parity estimates) per DALY averted. For the base-case we adopted a modified societal perspective and discounted future costs and disabilityadjusted and unadjusted life years by $3 \%$ annually [12-15]. We have also conducted a cost-effectiveness analysis from the perspective of local government. Sensitivity analyses were conducted to explore the influence of both uncertain parameters and assumptions on results. We projected the expected reduction in rotavirus disease burden and budget impact associated with a variety of scale-up scenarios.

\section{Model}

Simulation model of the natural history of rotavirus infection We have previously described a model of the natural history of rotavirus infection using TreeAge 2008 software (Williamstown, MA), which captures details such as the age-specific risk, probability of asymptomatic cases, rate of reinfection, correlation between strength of natural immunity and the total number of previous infections, and waning of vaccine efficacy [16]. We applied the model to Vietnam to reevaluate the cost-effectiveness of a rotavirus vaccination program [16]. We leveraged this work to develop a series of rotavirus disease models to explore uncertainties associated with analytic choices about model structure [17], and conducted corroboration exercises by comparing projected model outcomes to those obtained using the companion model described below.

\section{Excel-based companion model}

The companion rotavirus model has been developed to reflect the main features of rotavirus infection and vaccination, and to project the health and economic consequences at the population level, in settings where data are limited. The model is constructed as a static cohort simulation model and is programmed using Microsoft Excel 2003 and Visual Basic for Applications 6.3 (Microsoft Corporation, Redmond, Washington). The model employs simplifying assumptions that rely on insights from more complex natural history models [16,17]. The upper panel in Figure 1 shows the simplified schematic of natural history represented in the Excel-based companion model. Severe cases of rotavirus gastroenteritis are considered those which are symptomatic and requiring outpatient clinic visit or hospitalization or those resulting in disease-specific deaths [18].

The Excel-based companion model is applied to birth cohorts (born in 2010) in the 72 GAVI-eligible countries. 


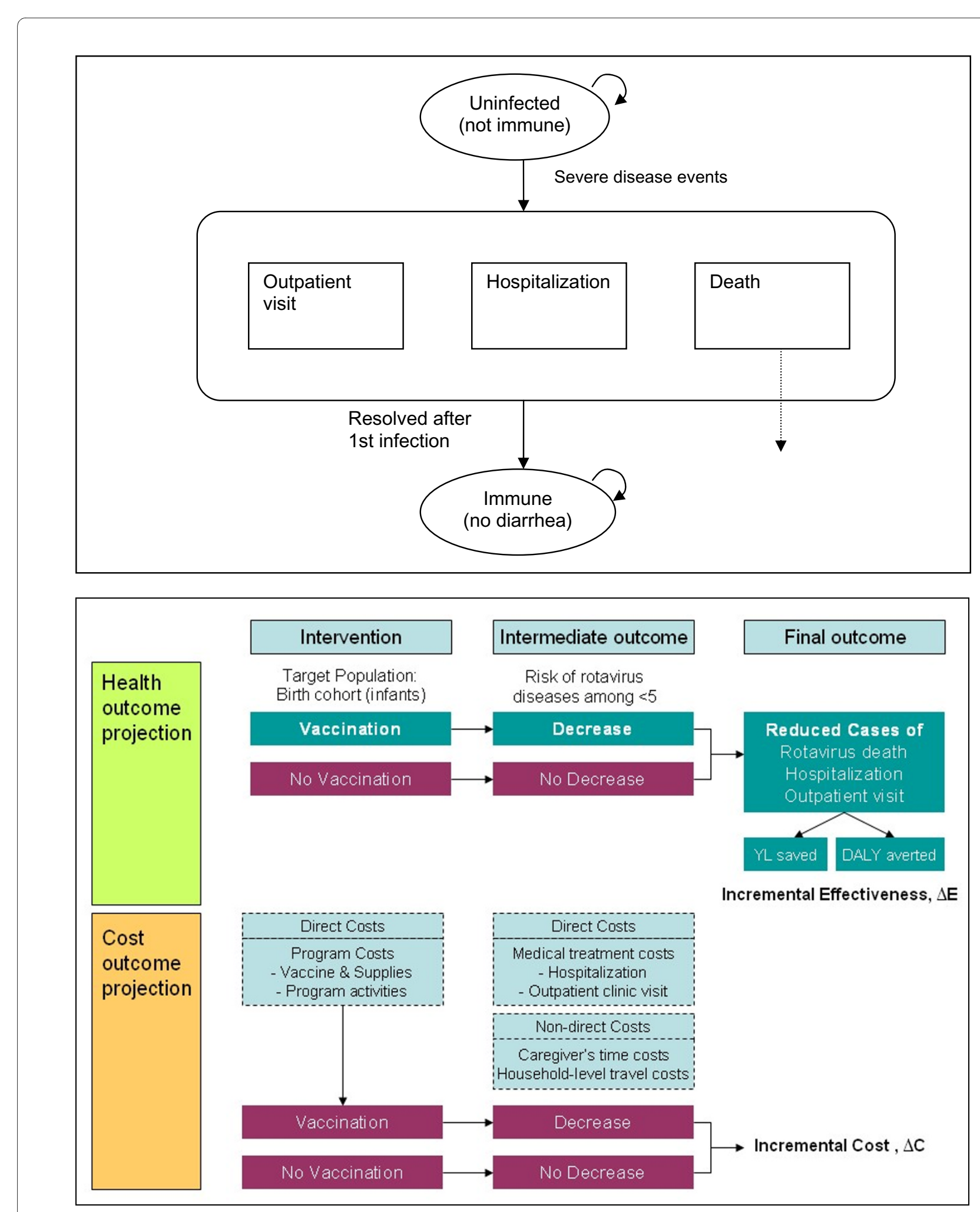

Figure 1 Schematic of the companion rotavirus model. Upper panel shows the schematic of the natural history model of rotavirus infection the companion model is based on. The model assumes one episode of rotavirus diarrhea at maximum and full protection against subsequent rotavirus diarrhea during the first 5 years of life of a vaccinated child. Lower panel presents the schematic of the companion model. 
The model tracks the cohorts up to age 5, incorporating background mortality and recording population-level health and cost outcomes with and without vaccination programs. Combining country-specific or region-specific data on the incidence of rotavirus deaths, ratios of outpatient visits or hospitalizations to rotavirus deaths, and serotype distribution, the model generates estimates for the reduction in rotavirus related events requiring medical treatments (i.e., outpatient clinic visits and hospitalizations) or leading to deaths. By applying the estimates to each country's age-structured population, the model transforms them into aggregated population health outcome measures, YL and DALYs (Figure 1, Lower Panel). DALYs are calculated using the approach recommended by the Global Burden of Disease (GBD) study [19] but are not age-weighted (age weight modulating factor $\mathrm{K}=0$ ) [20]. We assumed that the average mean duration of a diarrheal episode was 7 days and that each episode is associated with a disability weight of 0.119 [19]. The model also tracks direct medical and non-medical costs associated with rotavirus disease events and the costs of the vaccine program from the societal perspective. The primary measure for the cost-effectiveness analysis is expressed as the incremental costs (2005 I\$) per DALY averted. The model is also used to project the financial costs and disease burden reduction at the population level for a multi-year rotavirus vaccination program, varying assumptions to simulate different demand forecasting and scale-up scenarios.

\section{Model input and assumptions \\ Intervention: vaccine types and vaccination schedule}

The number of doses (and schedule) recommended by the vaccine manufacturers are 2 (at 2 and 4 months) for Rotarix and 3 (at 2,4, and 6 months) for Rotateq. Because this analysis is intended to provide a broad policy overview of the expected health and economic outcomes of rotavirus vaccination, and not to contextualize a detailed situation of a single specific country, we chose not to distinguish the two vaccines in terms of dose and schedule or vaccine efficacy. This decision was based in large part on the WHO SAGE recommendations and in part based on published evidence: 1) a 3-dose schedule is recommended in any setting where the two vaccines, Rotarix and Rotateq are interchangeably used [21];2) efficacy data for a rotavirus vaccine obtained in one population can be extrapolated to other populations if the two populations belong to the same under 5 mortality category [10]; and 3) in a phase III Rotarix trial performed in Malawi, the overall efficacy against severe rotavirus gastroenteritis of a 2-dose schedule (49.2\%) showed little difference compared to the corresponding value with a 3dose schedule (49.7\%) [10]. To first generate an estimate of the potential avertable global burden with rotavirus vaccination, we standardized an initial set of assumptions: 1) infants are given 3 doses of a rotavirus vaccine (Rotarix or Rotateq) at ages aligned with each countries EPI visits (or DTP schedule) (6,10, and 14 weeks or 2,4, and 6 months of age); 2) coverage is $70 \%$, (purposefully assumed in order to illustrate differences in country-specific outcomes related to variations in epidemiology); 3 ) vaccine-induced immunity is durable over 5 years without waning; and 4), for both vaccines, side effects are considered negligible as long as the first and last dose of either vaccine is given at the recommended age ranges (615 weeks for the first dose and 8 months or 32 weeks for the last dose) [21]. We then conducted additional analyses using a range of alternative assumptions (e.g., waning of vaccine-acquired immunity).

\section{Vaccine efficacy}

We used two different approaches for estimating vaccine efficacy. For the base-case analysis, recognizing that differences in rotavirus serotype distributions would affect the overall efficacy against severe types of rotavirus, we calculated a weighted average of serotype-specific vaccine efficacy using the country- or region-specific serotype distribution data. Data for rotavirus serotype distributions were obtained from published epidemiological studies. When country-specific data were not available, region-specific estimates reported by the global networks for rotavirus surveillance were used [11] (see Additional file 1 for details).

For a secondary analysis, based on the SAGE recommendation that efficacy data of a rotavirus vaccine can be extrapolated to other populations that have the same under 5 child mortality stratum, we divided the GAVI countries into the three categories (i.e., "high" mortality for the highest quartile, "intermediate" mortality for the second highest quartile, and "low" mortality for the lowest two quartiles [10]). We then extrapolated the pooled efficacy for a 2- or 3-dose schedule obtained from Malawi (49.5\%) [10] to GAVI-eligible countries that belong to the "high" child mortality stratum and the corresponding data from South Africa (76.9\%) [10] to the countries that fall on "intermediate" strata. Currently, there are no corresponding efficacy data obtained in low income countries with "low" under 5 mortality. Rather than using the data from industrialized countries with "low" under 5 mortality, we conservatively chose to use the data from South Africa for the low-child mortality GAVI-eligible countries. Under 5 mortality data to stratify countries for efficacy data extrapolation were obtained from the WHO World Health Statistics database [22] (Table 1).

\section{Demographic data and assumptions}

For country-specific age-structure that incorporates background mortality, we used the estimates of population size (1-year interval) from UN World Population Prospects 2006 Revision [23]. Age-specific life expec- 
Table 1: Country-specific profiles of the 72 GAVI-eligible countries

\begin{tabular}{|c|c|c|c|c|c|c|}
\hline Countrya & $\begin{array}{r}\text { GNI per capita } \\
\text { (2008 US\$) }\end{array}$ & $\begin{array}{l}\text { GAVI grouping } \\
\text { for co-financing }\end{array}$ & $\begin{array}{r}\text { DTP3 coverage } \\
(2008)\end{array}$ & $\begin{array}{r}\text { Under } 5 \text { child } \\
\text { mortality (per } \\
1,000 \text { live } \\
\text { births) }(2006)\end{array}$ & $\begin{array}{r}\text { Under } 5 \\
\text { rotavirus } \\
\text { mortality (per } \\
100000 \text { children } \\
<5)(2004)\end{array}$ & $\begin{array}{r}\text { Percentage of } \\
\text { death due to } \\
\text { diarrhea among } \\
\text { children under } \\
5(2000)\end{array}$ \\
\hline \multicolumn{7}{|l|}{ AFR D } \\
\hline Angola & 3,450 & 4 & $81 \%$ & 260 & 389 & 19.1 \\
\hline Benin & 690 & 1 & $93 \%$ & 148 & 182 & 17.1 \\
\hline Burkina Faso & 480 & 1 & $99 \%$ & 204 & 256 & 18.8 \\
\hline Cameroon & 1,150 & 3 & $84 \%$ & 149 & 179 & 17.3 \\
\hline Chad & 530 & 1 & $43 \%$ & 209 & 266 & 18.1 \\
\hline Comoros & 750 & 1 & $81 \%$ & 68 & 64 & 13.6 \\
\hline Ghana & 670 & 2 & $87 \%$ & 120 & 92 & 12.2 \\
\hline Guinea & 390 & 1 & $70 \%$ & 161 & 188 & 16.5 \\
\hline Guinea-Bissau & 250 & 1 & $79 \%$ & 200 & 283 & 18.6 \\
\hline Liberia & 170 & 4 & $92 \%$ & 235 & 331 & 17.3 \\
\hline Madagascar & 410 & 1 & $88 \%$ & 115 & 141 & 16.9 \\
\hline Mali & 580 & 1 & $99 \%$ & 217 & 307 & 18.3 \\
\hline Mauritania & 840 & 1 & $74 \%$ & 125 & 153 & 16.2 \\
\hline Niger & 330 & 1 & $89 \%$ & 253 & 392 & 19.8 \\
\hline Nigeria & 1,160 & 2 & $57 \%$ & 191 & 228 & 15.7 \\
\hline Sao Thome & 1,020 & 1 & $99 \%$ & 96 & 129 & 16.0 \\
\hline Senegal & 970 & 1 & $88 \%$ & 116 & 158 & 17.1 \\
\hline Sierra Leone & 320 & 4 & $87 \%$ & 269 & 439 & 19.7 \\
\hline The Gambia & 390 & 1 & $96 \%$ & 114 & 107 & 12.2 \\
\hline Togo & 400 & 1 & $89 \%$ & 107 & 134 & 13.8 \\
\hline \multicolumn{7}{|l|}{ AFRE } \\
\hline Burundi & 140 & 4 & $92 \%$ & 181 & 255 & 18.2 \\
\hline Central African Republic & 410 & 4 & $51 \%$ & 174 & 210 & 14.7 \\
\hline Congo & 1,970 & 4 & $89 \%$ & 126 & 86 & 11.2 \\
\hline Cote d'Ivoire & 980 & 4 & $74 \%$ & 127 & 223 & 14.8 \\
\hline $\begin{array}{l}\text { Democratic Republic of } \\
\text { the Congo }\end{array}$ & 150 & 4 & $83 \%$ & 205 & 281 & 18.1 \\
\hline Eritrea & 300 & 4 & $85 \%$ & 74 & 84 & 15.6 \\
\hline Ethiopia & 280 & 1 & $81 \%$ & 123 & 213 & 17.3 \\
\hline Kenya & 770 & 2 & $85 \%$ & 121 & 135 & 16.5 \\
\hline Lesotho & 1,080 & 1 & $91 \%$ & 132 & 25 & 3.9 \\
\hline Malawi & 290 & 1 & $91 \%$ & 120 & 225 & 18.1 \\
\hline Mozambique & 370 & 1 & $80 \%$ & 138 & 183 & 16.5 \\
\hline Rwanda & 410 & 1 & $97 \%$ & 160 & 272 & 18.5 \\
\hline Tanzania & 430 & 1 & $84 \%$ & 118 & 147 & 16.8 \\
\hline Uganda & 420 & 1 & $79 \%$ & 134 & 165 & 17.2 \\
\hline Zambia & 950 & 1 & $95 \%$ & 182 & 227 & 17.5 \\
\hline Zimbabwe & c & 2 & $75 \%$ & 85 & 106 & 12.1 \\
\hline \multicolumn{7}{|l|}{ AMR A, B \& D } \\
\hline Cuba & c & 2 & $99 \%$ & 7 & 1 & 1.3 \\
\hline Guyana & 1,420 & 3 & $93 \%$ & 62 & 119 & 21.4 \\
\hline Honduras & 1,800 & 3 & $93 \%$ & 27 & 43 & 12.2 \\
\hline Bolivia & 1,460 & 3 & $83 \%$ & 61 & 66 & 14.3 \\
\hline
\end{tabular}


Table 1: Country-specific profiles of the 72 GAVI-eligible countries (Continued)

\begin{tabular}{|c|c|c|c|c|c|c|}
\hline Haiti & 660 & 4 & $53 \%$ & 80 & 133 & 16.5 \\
\hline Nicaragua & 1,080 & 2 & $96 \%$ & 26 & 30 & 12.2 \\
\hline \multicolumn{7}{|l|}{ EMR D } \\
\hline Afghanistan & c & 4 & $85 \%$ & 257 & 338 & 18.9 \\
\hline Djibouti & 1,130 & 3 & $89 \%$ & 130 & 145 & 16.6 \\
\hline Pakistan & 980 & 2 & $73 \%$ & 97 & 95 & 14.0 \\
\hline Somalia & c & 4 & $31 \%$ & 145 & 315 & 18.7 \\
\hline Sudan & 1,130 & 4 & $93 \%$ & 89 & 79 & 12.9 \\
\hline Yemen & 950 & 1 & $87 \%$ & 100 & 108 & 16.1 \\
\hline \multicolumn{7}{|l|}{ EUR B \& C } \\
\hline Armenia & 3,350 & 3 & $89 \%$ & 24 & 29 & 10.5 \\
\hline Azerbaijan & 3,830 & 3 & $95 \%$ & 89 & 125 & 15.3 \\
\hline Georgia & 2,470 & 3 & $92 \%$ & 32 & 42 & 11.5 \\
\hline Kyrgyzstan & 740 & 2 & $95 \%$ & 41 & 86 & 14.1 \\
\hline Tajikistan & 600 & 2 & $86 \%$ & 68 & 177 & 16.4 \\
\hline Uzbekistan & 910 & 2 & $98 \%$ & 44 & 88 & 14.8 \\
\hline Moldova & 1,470 & 2 & $95 \%$ & 19 & 5 & 2.0 \\
\hline Ukraine & 3,210 & 3 & $90 \%$ & 24 & 2 & 1.2 \\
\hline \multicolumn{7}{|l|}{ SEAR B \& D } \\
\hline Indonesia & 2,010 & 3 & $77 \%$ & 34 & 60 & 18.3 \\
\hline $\begin{array}{l}\text { Korea, Democratic } \\
\text { Republic }\end{array}$ & c & 2 & $92 \%$ & 55 & 56 & 18.9 \\
\hline Sri Lanka & 1,790 & 3 & $98 \%$ & 13 & 16 & 13.5 \\
\hline Timor Leste & 2,460 & 4 & $79 \%$ & 55 & 115 & 21.9 \\
\hline Bangladesh & 520 & 1 & $87 \%$ & 69 & 89 & 20.0 \\
\hline Bhutan & 1,900 & 1 & $96 \%$ & 70 & 98 & 20.9 \\
\hline India & 1,070 & 2 & $84 \%$ & 76 & 102 & 20.3 \\
\hline Myanmar & c & 1 & $85 \%$ & 104 & 128 & 21.1 \\
\hline Nepal & 400 & 1 & $82 \%$ & 59 & 91 & 20.5 \\
\hline \multicolumn{7}{|l|}{ WPR B } \\
\hline Cambodia & 600 & 1 & $91 \%$ & 82 & 226 & 16.6 \\
\hline Kiribati & 2,000 & 3 & $82 \%$ & 64 & 127 & 21.9 \\
\hline $\begin{array}{l}\text { Lao People Democratic } \\
\text { Republic }\end{array}$ & 750 & 1 & $61 \%$ & 75 & 122 & 15.6 \\
\hline Mongolia & 1,680 & 2 & $96 \%$ & 42 & 67 & 14.5 \\
\hline Papua New Guinea & 1,010 & 2 & $52 \%$ & 73 & 128 & 15.3 \\
\hline Solomon Islands & 1,180 & 1 & $78 \%$ & 72 & 45 & 8.8 \\
\hline Viet Nam & 890 & 2 & $93 \%$ & 17 & 21 & 10.4 \\
\hline
\end{tabular}

a The six WHO geographical regions are the African Region (AFR), Eastern Mediterranean Region (EMR), Region of the Americas (AMR), European Region (EUR), South-East Asian Region (SEAR), and Western Pacific Region (WPR). Categories for mortality rates include very low child, very low adult mortality (A), low child, low adult mortality (B), low child, high adult mortality (C), high child, high adult mortality (D), and high child and very high adult mortality (E). Combining the two dimensions, we modeled 36 countries from AFR (with 20 in AFR D and 16 in AFR E); 6 countries from EMR D; 6 countries from AMR A, B \& D; 8 countries from EUR B \& $C ; 9$ countries from SEAR B \& D; and 7 countries from WPR B.

$b$ The GAVI Alliance new vaccine co-financing policy (which came into effect in 2008) requires GAVI-eligible countries to share new vaccine costs at one of four levels depending on the country's ability to pay: (1) Poorest group countries will pay $\$ 0.20 /$ dose of the first vaccine and $\$ 0.15 /$ dose for the $2^{\text {nd }}$ and $3^{\text {rd }}$ vaccines; (2) Intermediate group countries will pay $\$ 0.30 /$ dose of the first vaccine and $\$ 0.15 /$ dose for the $2^{\text {nd }}$ and $3^{\text {rd }}$ vaccines; $(3)$ Least Poor group countries will pay $\$ 0.20 /$ dose of the first vaccine and $\$ 0.15 /$ dose for the $2^{\text {nd }}$ and $3^{\text {rd }}$ vaccines for the first year, but will increase their copayment by $15 \%$ annually; and (4) Fragile group countries will pay $\$ 0.10 /$ dose of the first vaccine and $\$ 0.15 /$ dose for the $2^{\text {nd }}$ and $3^{\text {rd }}$ vaccines.

c Data are not available. 
tancy data (grouped in five-year intervals) for calculating years of life lost as a component of DALYs were obtained from WHO life tables (for year 2006) [24]. To facilitate comparison of the results across regions, for the present analysis, the 72 GAVI-eligible countries were clustered into 11 groups according to the WHO classification system, which is based on geographical location and mortality rates (see footnotes to Table 1).

\section{Incidence of rotavirus disease events}

We estimated age-specific incidence rates of rotavirusassociated deaths by applying regional estimates of age distribution (across ages $0,1,2,3$, and 4) of severe rotavirus gastroenteritis cases obtained from published literature $[16,25-28]$ to the WHO estimates of the countryspecific cumulative number of rotavirus deaths among children under 5 years of age [29] (Table 1). Incidence rates of outpatient visits or hospitalization vary widely depending on the health care infrastructure and resources available in a country. Estimates of countryspecific ratios of cumulative incidence of outpatient visits or hospitalizations to deaths were obtained from published literature; when country-specific data were not available, regional estimates or neighboring countries' values were used. The age-specific incidence rates for non-fatal outcomes were then estimated by adjusting cumulative incidence of each outcome by the same age distribution data mentioned above.

\section{Costs}

Costs included both direct medical costs (vaccination program costs plus medical treatment costs) and indirect costs (travel costs and caregivers' time costs). Since the price of a rotavirus vaccine and program costs to deliver the vaccine in local settings are not known, we use a composite cost approach to estimate the vaccination program costs among the direct, medical costs. In doing so, we distinguish cost items that are tradable (e.g., vaccine wastage, insurance and security fees associated with freight into the country) from those that are typically non-tradable (e.g., administration, immunization support and monitoring/programmatic expenses). We conduct analyses assuming a 3-dose vaccination schedule with total cost per vaccinated child of I $\$ 10$ and of I $\$ 25$, implying vaccine prices per dose of approximately US $\$ 1.50$ and US $\$ 5.00$ respectively. For a composite cost of I $\$ 25$ per vaccinated child, we assume the following breakdown of the total costs: rotavirus vaccine purchase of US $\$ 15.00$ (3 doses at US\$5.00 each); vaccine wastage of approximately US\$2.65 ( 15\% of vaccine price); freight and insurance costs of approximately US $\$ 0.90$ ( $\sim 6 \%$ of vaccine price); administrative costs of $\mathbf{I} \$ 1.50$; immunization support (including cold chain, training, and operational costs) of I\$2.95; and other programmatic costs (including surveillance and monitoring and social mobilization) of I\$2.00. The lower cost of $\mathbf{I} 10$ was derived by assuming 3 doses of vaccine at US\$1.50 each, wastage of approximately US $\$ 0.79$, freight and insurance costs of approximately US $\$ 0.27$, administrative costs of I $\$ 0.50$, immunization support of I\$2.00, and programmatic costs of I\$1.94. For both composite cost estimates, we assumed that the costs reflect any initial start-up cost and that the non-tradable components (such as administration, immunization support and other programmatic costs) would reflect incremental costs associated with introducing rotavirus vaccines into a national immunization programs to varying extents, depending on countries' health system infrastructure.

Costs for hospitalization were based on country-specific data. When data were not available, we based estimates on WHO-CHOICE data for the cost of a bed-day at a secondary hospital, conservatively assuming one prehospitalization consultation in an outpatient setting, onetime hospitalization, and an average length of stay of 3 days for hospitalization (see also Additional file 1). Similarly, costs for outpatient visits were based on countryspecific data when available, and, when data were not available, were based on the use of WHO-CHOICE data for a 20 -minute visit at health center (80\% coverage) assuming one visit per episode. We calculated caregiver's time for hospitalization or outpatient visit by multiplying an average length of stay for hospitalization ( 3 days $\times 8$ hours/day) or an average length of an outpatient visit (6 hours) by an estimated country-specific average hourly wage. The average hourly wage data for each country were estimated by analyzing the data from the Labor Statistics database [30] and the World Development Indicators [31], taking into account unemployment and underemployment rate and distribution of the main industries in a country (Additional file 1). We obtained estimates of average transport costs for a visit to medical facilities from published studies for some countries and extrapolated the data to countries in the same region for which country-specific estimates were not available (Additional file 1).

\section{Cost-effectiveness analysis}

For the base-case, we estimated the cost-effectiveness of a rotavirus program in the $72 \mathrm{GAVI}$-eligible countries from the societal perspective, following a single birth cohort over a 5-year time horizon. The primary outcome measure of the analysis was incremental cost-effectiveness ratio (expressed in 2005 I\$ per DALY averted). The incremental cost is the sum of vaccination program costs, averted medical treatment costs for children, and averted caregivers' time and travel costs. We have also evaluated the cost-effectiveness of rotavirus vaccination from the local government perspective, including direct medical costs only and adjusting vaccine costs using the GAVI's co-financing scheme for new vaccines [32] (see footnotes 
to Table 1 for details). The government savings from the averted medical treatment costs were calculated by adjusting the total averted medical costs for the public sector's percentages of total health expenditure [31].

\section{Sensitivity analysis}

In order to explore uncertainties surrounding model projected outcomes, we performed univariate sensitivity analyses, varying key parameter values and assumptions one at a time. For example, in a sensitivity analysis, we assumed that vaccine efficacy against severe rotavirus diseases would decline over a 5 -year time horizon by $\sim 14 \%$ annually, based on 2-year efficacy data obtained from a published study [33]. We have also conducted multivariate sensitivity analyses by developing multiple scenarios based on different combinations of analytic choices (e.g., discount rate or perspective), efficacy levels, vaccination program costs, etc.

\section{Budget impact analysis and scale-up scenarios}

When considering whether to introduce a new vaccine into a national immunization program, local policy makers need information on total cost as well as value for money, in order to assess the affordability and sustainability of a vaccination program. To provide policymakers with more practical budgetary information, we conducted a budget impact analysis over a 10-year time horizon (2010-2019) from the perspective of budget holders (i.e., local governments) $[34,35]$ by extending the basecase analysis using the same Excel-based model. We first developed alternative roll-out scenarios (i.e., vaccination introduced at different coverage levels), in which the year of rotavirus vaccine introduction, maximum achievable coverage rate, and years to full coverage were varied across countries. The financial forecasts are based on the program cost per child of I $\$ 25$ (i.e., US $\$ 5$ per vaccine dose). We calculated the vaccine costs to local governments according to the GAVI's co-financing scheme [32] (Table 1), but used the same composite approach as the base-case cost-effectiveness analysis in estimating the incremental costs of delivering rotavirus vaccines. The financial forecasts were expressed in US\$ because budgets are typically expressed in nominal rather than real terms. Note that the financial requirements are not discounted, based on the published guidelines that discounting is not necessary for budget impact analysis $[34,35]$.

For the base-case roll-out scenario, building upon the two previous approaches-an explicit 2-Phase scenario envisioned by Artherly et al. [36] and Wolfson et al.'s approach [37], we categorized the 72 GAVI-eligible countries into 10 groups according to each country's national income level (2008) (Table 1), the most recent year's DPT3 (the third dose of Diptheria-Pertussis-Tetanus vaccine) coverage (Table 1), past history of new vaccine (i.e.,
Hib or HepB vaccines) introduction, and Artherly and colleagues' demand forecasting results [36]. Table 2 presents the details of the 10 categories and rotavirus vaccine demand forecasting for 10 consecutive cohorts being introduced between 2010-2019 for each country. Following the approach used by Wolfson et al. [37], we used DTP3 coverage from 2008 (the most recent year available) as a proxy for a full coverage. We also used the past trends in the coverage of Hib, HepB, and DTP3 to forecast years of first introduction and years to full coverage. We then assumed that 1) countries in Category 1 roll out in Year 1 (2010), and countries in Category 2 roll out in 2011, etc., with countries in Category 10 rolling out in Year 10 (2019). (Note that, because Nicaragua has already introduced Rotarix, we use 2006 as their start date.); 2) it takes 2 or 3 years after implementation to reach full coverage for Category 1, 4 years for Categories 2 and 3, 5 years for Categories 4-6, 6 years for Categories 7-8, and 7 years for Categories 9-10; and 3) once full coverage is achieved, the coverage level would be maintained (Table 2). We also evaluated alternative, more optimistic roll-out scenarios by using Wolfson et al.'s original assumptions adjusted with the most recent year's data for GNI per capita and DTP3 coverage [37] and by assuming a flat coverage of $70 \%$ over a 10 -year period.

\section{Results}

\section{Model validation}

To ensure that the companion population-based model produced results consistent with our state-transition model when both were subject to our simplifying assumptions, we compared projected health outcomes and cost-effectiveness from the two different models for Vietnam. While the absolute averted deaths reflects both epidemiological differences in the incidence and proportion of vaccine-targeted serotypes, the cost-effectiveness ratios estimated using the two models differ by less than 5\% (data not shown). Our previous work [17], which explored model uncertainty by comparing results from five different models of the natural history of rotavirus infection, also reaffirmed that our companion model yielded results consistent with those from more complex natural history models. According to the previous analysis [17], within the category of static, deterministic, aggregate-level models, different choices in model structure lead to relatively modest differences in the estimated cost-effectiveness of rotavirus vaccination while intermediate "non-severe" epidemiologic outcomes vary more substantially depending on choices of model structure.

\section{Health outcomes}

Under the base-case assumptions (70\% coverage, a limit of one rotavirus disease event per child over the first 5 years of life, and vaccine efficacy against severe rotavirus 
Table 2: Implied coverage rates for a base-case scale-up scenario (\%)

\begin{tabular}{|c|c|c|c|c|c|c|c|c|c|c|c|}
\hline \multirow[t]{2}{*}{ Country } & \multirow[t]{2}{*}{ Categorya } & \multirow{2}{*}{$\begin{array}{l}\text { Year } 1 \\
2010\end{array}$} & \multirow{2}{*}{$\begin{array}{r}\text { Year } 2 \\
2011\end{array}$} & \multirow{2}{*}{\begin{tabular}{|r|} 
Year 3 \\
2012 \\
\end{tabular}} & \multirow{2}{*}{\begin{tabular}{|c|} 
Year 4 \\
2013
\end{tabular}} & \multirow{2}{*}{\begin{tabular}{|c|} 
Year 5 \\
2014 \\
\end{tabular}} & \multirow{2}{*}{$\begin{array}{r}\text { Year } 6 \\
2015\end{array}$} & \multirow{2}{*}{$\begin{array}{r}\text { Year } 7 \\
2016 \\
\end{array}$} & \multirow{2}{*}{$\begin{array}{r}\text { Year } 8 \\
2017\end{array}$} & \multirow{2}{*}{$\begin{array}{r}\text { Year } 9 \\
2018\end{array}$} & \multirow{2}{*}{$\begin{array}{r}\text { Year 10 } \\
2019\end{array}$} \\
\hline & & & & & & & & & & & \\
\hline \multicolumn{12}{|l|}{ AFR D } \\
\hline Angola & 10 & & & & & & & & & & 31.0 \\
\hline Benin & 5 & & & & & 15.0 & 30.6 & 46.2 & 61.8 & 77.4 & 93.0 \\
\hline Burkina Faso & 5 & & & & & 57.0 & 65.4 & 73.8 & 82.2 & 90.6 & 99.0 \\
\hline Cameroon & 3 & & & 53.0 & 60.8 & 68.5 & 76.3 & 84.0 & 84.0 & 84.0 & 84.0 \\
\hline Chad & 8 & & & & & & & & 28.0 & 30.5 & 33.0 \\
\hline Comoros & 7 & & & & & & & 27.0 & 36.0 & 45.0 & 54.0 \\
\hline Ghana & 6 & & & & & & 80.0 & 81.4 & 82.8 & 84.2 & 85.6 \\
\hline Guinea & 8 & & & & & & & & 57.0 & 59.2 & 61.3 \\
\hline Guinea-Bissau & 9 & & & & & & & & & 47.0 & 51.6 \\
\hline Liberia & 5 & & & & & 48.0 & 56.8 & 65.6 & 74.4 & 83.2 & 92.0 \\
\hline Madagascar & 6 & & & & & & 61.0 & 66.4 & 71.8 & 77.2 & 82.6 \\
\hline Mali & 5 & & & & & 54.0 & 63.0 & 72.0 & 81.0 & 90.0 & 99.0 \\
\hline Mauritania & 8 & & & & & & & & 31.0 & 38.2 & 45.3 \\
\hline Niger & 9 & & & & & & & & & 25.0 & 34.1 \\
\hline Nigeria & 4 & & & & 41.0 & 44.2 & 47.4 & 50.6 & 53.8 & 57.0 & 57.0 \\
\hline Sao Tome & 3 & & & 43.0 & 57.0 & 71.0 & 85.0 & 99.0 & 99.0 & 99.0 & 99.0 \\
\hline Senegal & 6 & & & & & & 54.0 & 60.8 & 67.6 & 74.4 & 81.2 \\
\hline Sierra Leone & 6 & & & & & & 24.0 & 36.6 & 49.2 & 61.8 & 74.4 \\
\hline The Gambia & 5 & & & & & 84.0 & 86.4 & 88.8 & 91.2 & 93.6 & 96.0 \\
\hline Togo & 6 & & & & & & 50.0 & 57.8 & 65.6 & 73.4 & 81.2 \\
\hline \multicolumn{12}{|l|}{ AFRE } \\
\hline Burundi & 10 & & & & & & & & & & 74.0 \\
\hline Central African Republic & 10 & & & & & & & & & & 29.0 \\
\hline Congo & 10 & & & & & & & & & & 33.0 \\
\hline Cote d'Ivoire & 4 & & & & 10.0 & 22.8 & 35.6 & 48.4 & 61.2 & 74.0 & 74.0 \\
\hline $\begin{array}{l}\text { Democratic Republic of the } \\
\text { Congo }\end{array}$ & 10 & & & & & & & & & & 40.0 \\
\hline Eritrea & 6 & & & & & & 52.0 & 58.6 & 65.2 & 71.8 & 78.4 \\
\hline Ethiopia & 6 & & & & & & 42.0 & 49.8 & 57.6 & 65.4 & 73.2 \\
\hline Kenya & 6 & & & & & & 72.0 & 74.6 & 77.2 & 79.8 & 82.4 \\
\hline Lesotho & 3 & & & 14.0 & 33.3 & 52.5 & 71.8 & 91.0 & 91.0 & 91.0 & 91.0 \\
\hline Malawi & 5 & & & & & 64.0 & 69.4 & 74.8 & 80.2 & 85.6 & 91.0 \\
\hline Mozambique & 8 & & & & & & & & 25.0 & 34.2 & 43.3 \\
\hline Rwanda & 5 & & & & & 88.0 & 89.8 & 91.6 & 93.4 & 95.2 & 97.0 \\
\hline Tanzania & 7 & & & & & & & 79.0 & 79.8 & 80.7 & 81.5 \\
\hline Uganda & 8 & & & & & & & & 29.0 & 37.3 & 45.7 \\
\hline Zambia & 5 & & & & & 80.0 & 83.0 & 86.0 & 89.0 & 92.0 & 95.0 \\
\hline Zimbabwe & 8 & & & & & & & & 9.0 & 20.0 & 31.0 \\
\hline \multicolumn{12}{|l|}{ AMR A, B \& D } \\
\hline Cuba & 1 & 93.0 & 95.0 & 97.0 & 99.0 & 99.0 & 99.0 & 99.0 & 99.0 & 99.0 & 99.0 \\
\hline Guyana & 1 & 89.0 & 93.0 & 93.0 & 93.0 & 93.0 & 93.0 & 93.0 & 93.0 & 93.0 & 93.0 \\
\hline Honduras & 1 & 84.0 & 93.0 & 93.0 & 93.0 & 93.0 & 93.0 & 93.0 & 93.0 & 93.0 & 93.0 \\
\hline Bolivia & 1 & 82.0 & 83.0 & 83.0 & 83.0 & 83.0 & 83.0 & 83.0 & 83.0 & 83.0 & 83.0 \\
\hline Haiti & 10 & & & & & & & & & & 39.0 \\
\hline
\end{tabular}


Table 2: Implied coverage rates for a base-case scale-up scenario (\%) (Continued)

\begin{tabular}{|c|c|c|c|c|c|c|c|c|c|c|c|}
\hline Nicaragua & $1^{b}$ & 96.0 & 96.0 & 96.0 & 96.0 & 96.0 & 96.0 & 96.0 & 96.0 & 96.0 & 96.0 \\
\hline \multicolumn{12}{|l|}{ EMR D } \\
\hline Afghanistan & 10 & & & & & & & & & & 31.0 \\
\hline Djibouti & 2 & & 46.0 & 56.8 & 67.5 & 78.3 & 89.0 & 89.0 & 89.0 & 89.0 & 89.0 \\
\hline Pakistan & 4 & & & & 63.0 & 65.0 & 67.0 & 69.0 & 71.0 & 73.0 & 73.0 \\
\hline Somalia & 9 & & & & & & & & & 33.0 & 32.7 \\
\hline Sudan & 3 & & & 22.0 & 39.8 & 57.5 & 75.3 & 93.0 & 93.0 & 93.0 & 93.0 \\
\hline Yemen & 6 & & & & & & 9.0 & 24.6 & 40.2 & 55.8 & 71.4 \\
\hline \multicolumn{12}{|l|}{ EUR B \& C } \\
\hline Armenia & 1 & 55.0 & 66.3 & 77.7 & 89.0 & 89.0 & 89.0 & 89.0 & 89.0 & 89.0 & 89.0 \\
\hline Azerbaijan & 1 & 95.0 & 95.0 & 95.0 & 95.0 & 95.0 & 95.0 & 95.0 & 95.0 & 95.0 & 95.0 \\
\hline Georgia & 1 & 55.0 & 67.3 & 79.7 & 92.0 & 92.0 & 92.0 & 92.0 & 92.0 & 92.0 & 92.0 \\
\hline Kyrgyzstan & 1 & 10.0 & 38.3 & 66.7 & 95.0 & 95.0 & 95.0 & 95.0 & 95.0 & 95.0 & 95.0 \\
\hline Tajikistan & 1 & 39.0 & 54.7 & 70.3 & 86.0 & 86.0 & 86.0 & 86.0 & 86.0 & 86.0 & 86.0 \\
\hline Uzbekistan & 1 & 5.0 & 36.0 & 67.0 & 98.0 & 98.0 & 98.0 & 98.0 & 98.0 & 98.0 & 98.0 \\
\hline Moldova & 1 & 81.0 & 85.7 & 90.3 & 95.0 & 95.0 & 95.0 & 95.0 & 95.0 & 95.0 & 95.0 \\
\hline Ukraine & 1 & 4.0 & 32.7 & 61.3 & 90.0 & 90.0 & 90.0 & 90.0 & 90.0 & 90.0 & 90.0 \\
\hline \multicolumn{12}{|l|}{ SEAR B \& D } \\
\hline Indonesia & 4 & & & & 42.0 & 49.0 & 56.0 & 63.0 & 70.0 & 77.0 & 77.0 \\
\hline $\begin{array}{l}\text { Korea, Democratic } \\
\text { Republic }\end{array}$ & 10 & & & & & & & & & & 27.0 \\
\hline Sri Lanka & 3 & & & 62.0 & 71.0 & 80.0 & 89.0 & 98.0 & 98.0 & 98.0 & 98.0 \\
\hline Timor Leste & 4 & & & & 57.0 & 61.4 & 65.8 & 70.2 & 74.6 & 79.0 & 79.0 \\
\hline Bangladesh & 7 & & & & & & & 5.0 & 18.7 & 32.3 & 46.0 \\
\hline Bhutan & 3 & & & 90.0 & 91.5 & 93.0 & 94.5 & 96.0 & 96.0 & 96.0 & 96.0 \\
\hline India & 3 & & & 6.0 & 25.5 & 45.0 & 64.5 & 84.0 & 84.0 & 84.0 & 84.0 \\
\hline Myanmar & 7 & & & & & & & 8.0 & 20.8 & 33.7 & 46.5 \\
\hline Nepal & 7 & & & & & & & 2.0 & 15.3 & 28.7 & 42.0 \\
\hline \multicolumn{12}{|l|}{ WPR B } \\
\hline Cambodia & 5 & & & & & 50.0 & 58.2 & 66.4 & 74.6 & 82.8 & 91.0 \\
\hline Kiribati & 2 & & 36.0 & 47.5 & 59.0 & 70.5 & 82.0 & 82.0 & 82.0 & 82.0 & 82.0 \\
\hline $\begin{array}{l}\text { Lao People Democratic } \\
\text { Republic }\end{array}$ & 8 & & & & & & & & 50.0 & 51.8 & 53.7 \\
\hline Mongolia & 2 & & 95.0 & 95.3 & 95.5 & 95.8 & 96.0 & 96.0 & 96.0 & 96.0 & 96.0 \\
\hline Papua New Guinea & 4 & & & & 60.0 & 58.4 & 56.8 & 55.2 & 53.6 & 52.0 & 52.0 \\
\hline Solomon Islands & 2 & & 53.0 & 59.3 & 65.5 & 71.8 & 78.0 & 78.0 & 78.0 & 78.0 & 78.0 \\
\hline Viet Nam & 5 & & & & & 78.0 & 81.0 & 84.0 & 87.0 & 90.0 & 93.0 \\
\hline
\end{tabular}

a The profile of each category is as follows:

Category 1: 13 countries classified by Atherly et al.'s demand forecasting study [36] as "Phase 1" countries that are likely to introduce rotavirus vaccines earlier than other countries.

Category 2: Lower middle per capita income $(\$ 976-3,705)$ and introduction of both Hib and HepB vaccines.

Category 3: Lower middle per capita income $(\$ 976-3,705)$, either Hib or HepB vaccine introduction, and high $(>80 \%)$ to very high $(>90 \%)$ DTP3 coverage.

Category 4: Lower middle per capita income $(\$ 976-3,705)$, either Hib or HepB vaccine introduction, and low $(<70 \%)$ to moderate $(>70 \%)$ DTP3 coverage.

Category 5: Low income $(<\$ 975)$, Hib or HepB vaccine introduction, and very high ( $>90 \%)$ DTP3 coverage.

Category 6: Low income $(<\$ 975)$, both Hib and HepB vaccine introduction, and high $(>80 \%)$ DTP3 coverage.

Category 7: Low income ( $<\$ 975)$, either Hib or HepB vaccine introduction, and high ( $>80 \%)$ DTP3 coverage.

Category 8: Low income ( $<\$ 975)$, either Hib or HepB vaccine introduction, and low $(<70 \%)$ to moderate $(>70 \%)$ DTP3 coverage.

Category 9: Low income $(<\$ 975)$, neither Hib nor HepB vaccine introduction.

Category 10: 8 countries judged by Atherly et al. [36] to be countries that are not likely to introduce rotavirus vaccines.

b Introduced rotavirus vaccine in 2006. 
cases adjusted for country-specific serotype distribution), vaccinating one single birth cohort would prevent approximately $52 \%$ (range: $50 \%-59 \%$ ) of severe rotavirus disease events across the 72 GAVI-eligible countries compared to no vaccination (Table 3). However, the distribution of the absolute numbers of the reduced rotavirus disease burden would vary across regions or countries according to the varying levels of risk of rotavirus death. The number of rotavirus deaths averted per 1,000 vaccinated children varied from near 0 (Cuba) to 16 (Sierra Leone) (Table 3). The upper panel of Figure 2 shows that more than a half of the absolute global reduction (in terms of DALYs) would occur in the African region, and that the South-East Asian Region is another region that would benefit greatly from rotavirus vaccine introduction. The lower panel of Figure 2 indicates that the highest reduction in burden would be achieved in countries with a high disease burden $(\geq 200$ rotavirus deaths per 100,000 children under 5 years of age) but a similar reduction would be achieved in countries with a medium burden (100-200 rotavirus deaths per 100,000 children under 5 years of age) because reduction in disease burden also depends heavily on population size and country-specific vaccine efficacy adjusted for local rotavirus serotype distributions.

\section{Cost-effectiveness}

Table 4 shows the incremental cost-effectiveness ratios of a rotavirus vaccination program in each of the 72 countries for the two different estimated total costs per vaccinated child of I $\$ 10$ and I $\$ 25$, which correspond to the per dose vaccine costs of US $\$ 1.5$ and US $\$ 5$. Assuming I $\$ 25$ per vaccinated child for the base-case, the number of countries with the incremental cost per DALY averted less than I\$100 was 23 . Among the rest of the countries, the corresponding ratios of 24 countries fell between I $\$ 100-I \$ 200$. It should be noted that the incremental cost per DALY averted was relatively high in four countries (Cuba, I\$28,440; Moldova, I\$4,500; Sri Lanka, I\$1,300; and Ukraine, I\$12,160), mainly due to their relatively low rotavirus mortality (Cuba, 1; Moldova, 5; Sri Lanka, 16; and Ukraine, 2 per 100,000 children under age 5). Assuming I $\$ 10$ per vaccinated child, rotavirus infant vaccination would be cost-saving in 10 countries, and, in another 55 countries, the incremental cost per DALY averted would be less than I\$200. However, in the four countries with relatively low rotavirus disease burden, the ratios would still be relatively high, with $I \$ 11,330, I \$ 1,760, I \$ 490$, and I $\$ 4,820$, respectively, for Cuba, Moldova, Sri Lanka, and Ukraine. Table 4 also presents the cost-effectiveness results from the local government perspective, in which the per-child vaccination program costs accrued to local governments range between I\$10.3-I\$10.6 (depending on the level of national income and the history of other new vaccine introduction) when assuming US $\$ 5$ per vaccine dose in the market. The results suggest that, under this alternative government perspective, rotavirus vaccination would be considered more cost-effective than for the base-case societal perspective, presumably due to the financial support for vaccine purchase from GAVI.

While there is no consensus on a threshold cost-effectiveness ratio under which an intervention is cost-effective, a useful proxy suggested by WHO to compare different public health interventions is per capita GDP [38]. In this context, to facilitate comparison of the costeffectiveness of rotavirus vaccines in different settings, we compared the base-case results with each country's per capita GDP and found that a rotavirus vaccination program would be cost-effective in all GAVI countries except the four with relatively low rotavirus death rates (Table 4).

\section{Sensitivity analyses}

Results were most sensitive to vaccination cost per child, rotavirus-associated mortality, ratios of hospitalizations and outpatient visits to deaths, vaccine efficacy against severe gastroenteritis, and the discount rate. For example, at a total cost per vaccinated child of $\mathrm{I} \$ 5$, rotavirus vaccination was shown to be cost-saving in 54 countries and for the rest of the countries (except for Cuba, Moldova, Sri Lanka, and Ukraine) the incremental cost-effectiveness ratios ranged between I\$1-I\$170 per DALY averted. With a total cost per vaccinated child of I $\$ 50$, rotavirus vaccines were not cost-saving in any GAVI-eligible countries. Results were moderately sensitive to hospitalization, outpatient visit costs, and level of vaccine immunity waning. When we decreased age-specific vaccine efficacy by $\sim 14 \%$ annually over a 5 -year time horizon in India, for instance, the incremental cost per DALY averted (at I $\$ 25$ per child) increased from I $\$ 200$ to I $\$ 220$. The results were robust to duration of the disease, disability weight for diarrhea, transportation cost per visit, length of stay for hospitalization, and time per outpatient visit.

When we used standard age weighting $(K=1)$ [19] instead of uniform age weighting $(K=0)$, outcomes looked more favorable. For example, using $\mathrm{K}=1$, the total numbers of DALYs averted (discounted at 3\%) among the 72 GAVI-eligible countries increased to $~ 8.1$ million (compared to $\sim 7.1$ million with $\mathrm{K}=0$ ), and the incremental costs per DALY averted decreased by approximately 9$13 \%$ for each of the GAVI-eligible countries.

We conducted analyses using alternative vaccine efficacy data by following the WHO SAGE recommendation for efficacy data extrapolation across countries. The average rotavirus death reduction for the GAVI-eligible countries was reduced to $\sim 41 \%$ (compared to $\sim 52 \%$ ), since the average vaccine efficacy against severe rotavirus diseases was lower using this approach than calculating based on 
Table 3: Health outcomes of rotavirus vaccination in the GAVI-eligible countries

\begin{tabular}{|c|c|c|c|c|c|c|}
\hline \multirow[t]{2}{*}{ Country } & \multicolumn{3}{|c|}{$\begin{array}{c}\text { Base-case vaccine efficacy (adjusted for } \\
\text { serotype distribution) }\end{array}$} & \multicolumn{3}{|c|}{$\begin{array}{l}\text { Vaccine efficacy based on SAGE } \\
\text { recommendation }\end{array}$} \\
\hline & $\begin{array}{l}\text { Reduction in } \\
\text { risk of severe } \\
\text { rotavirus } \\
\text { disease events }\end{array}$ & $\begin{array}{r}\text { Rotavirus deaths } \\
\text { averted (per } \\
1000 \text { vaccinated } \\
\text { children) }\end{array}$ & $\begin{array}{r}\text { DALYs } \\
\text { averted }\end{array}$ & $\begin{array}{r}\text { Reduction in risk } \\
\text { of severe } \\
\text { rotavirus disease } \\
\text { events }\end{array}$ & $\begin{array}{r}\text { Rotavirus deaths } \\
\text { averted (per } \\
1000 \text { vaccinated } \\
\text { children) }\end{array}$ & $\begin{array}{r}\text { DALYs } \\
\text { averted }\end{array}$ \\
\hline \multicolumn{7}{|l|}{ AFR D } \\
\hline Angola & $55 \%$ & 14.2 & 176,385 & $35 \%$ & 9.0 & 111,341 \\
\hline Benin & $55 \%$ & 6.7 & 42,644 & $35 \%$ & 4.2 & 26,918 \\
\hline Burkina Faso & $50 \%$ & 8.6 & 92,836 & $35 \%$ & 5.9 & 63,999 \\
\hline Cameroon & $54 \%$ & 6.6 & 67,042 & $35 \%$ & 4.2 & 42,761 \\
\hline Chad & $55 \%$ & 9.8 & 76,358 & $35 \%$ & 6.2 & 48,200 \\
\hline Comoros & $55 \%$ & 2.4 & 1,245 & $54 \%$ & 2.3 & 1,221 \\
\hline Ghana & $59 \%$ & 3.7 & 44,965 & $35 \%$ & 2.2 & 26,291 \\
\hline Guinea & $55 \%$ & 6.9 & 43,736 & $35 \%$ & 4.3 & 27,608 \\
\hline Guinea-Bissau & $50 \%$ & 9.5 & 13,602 & $35 \%$ & 6.5 & 9,366 \\
\hline Liberia & $55 \%$ & 12.1 & 38,173 & $35 \%$ & 7.6 & 24,096 \\
\hline Madagascar & $55 \%$ & 5.2 & 68,520 & $35 \%$ & 3.3 & 43,252 \\
\hline Mali & $55 \%$ & 11.1 & 110,369 & $35 \%$ & 7.0 & 69,669 \\
\hline Mauritania & $55 \%$ & 5.7 & 10,359 & $35 \%$ & 3.6 & 6,539 \\
\hline Niger & $55 \%$ & 14.4 & 160,612 & $35 \%$ & 9.1 & 101,384 \\
\hline Nigeria & $51 \%$ & 7.7 & 733,421 & $35 \%$ & 5.3 & 498,170 \\
\hline Sao Thome & $55 \%$ & 4.7 & 430 & $35 \%$ & 3.0 & 272 \\
\hline Senegal & $55 \%$ & 5.8 & 45,473 & $35 \%$ & 3.7 & 28,704 \\
\hline Sierra Leone & $55 \%$ & 15.9 & 62,305 & $35 \%$ & 10.1 & 39,329 \\
\hline The Gambia & $55 \%$ & 4.0 & 4,250 & $35 \%$ & 2.5 & 2,682 \\
\hline Togo & $55 \%$ & 5.0 & 21,192 & $35 \%$ & 3.1 & 13,377 \\
\hline \multicolumn{7}{|l|}{ AFRE } \\
\hline Burundi & $55 \%$ & 9.3 & 67,442 & $35 \%$ & 5.8 & 42,572 \\
\hline Central African Republic & $55 \%$ & 7.7 & 19,559 & $35 \%$ & 4.8 & 12,346 \\
\hline Congo & $55 \%$ & 3.2 & 7,180 & $35 \%$ & 2.0 & 4,532 \\
\hline Cote d'Ivoire & $51 \%$ & 7.6 & 85,210 & $35 \%$ & 5.2 & 57,935 \\
\hline Democratic Republic of the Congo & $55 \%$ & 10.3 & 541,455 & $35 \%$ & 6.5 & 341,786 \\
\hline Eritrea & $55 \%$ & 3.1 & 11,263 & $54 \%$ & 3.0 & 11,045 \\
\hline Ethiopia & $55 \%$ & 7.8 & 443,905 & $35 \%$ & 4.9 & 280,209 \\
\hline Kenya & $55 \%$ & 5.0 & 132,053 & $35 \%$ & 3.1 & 83,357 \\
\hline Lesotho & $55 \%$ & 0.9 & 838 & $35 \%$ & 0.6 & 529 \\
\hline Malawi & $57 \%$ & 8.6 & 81,905 & $35 \%$ & 5.2 & 50,027 \\
\hline Mozambique & $55 \%$ & 6.8 & 90,101 & $35 \%$ & 4.3 & 56,875 \\
\hline Rwanda & $55 \%$ & 9.9 & 75,890 & $35 \%$ & 6.2 & 47,905 \\
\hline Tanzania & $57 \%$ & 5.5 & 146,305 & $35 \%$ & 3.4 & 89,138 \\
\hline Uganda & $55 \%$ & 6.0 & 153,907 & $35 \%$ & 3.8 & 97,151 \\
\hline Zambia & $51 \%$ & 7.8 & 56,160 & $35 \%$ & 5.3 & 37,952 \\
\hline Zimbabwe & $52 \%$ & 3.6 & 21,407 & $35 \%$ & 2.4 & 14,392 \\
\hline
\end{tabular}


Table 3: Health outcomes of rotavirus vaccination in the GAVI-eligible countries (Continued)

\begin{tabular}{|c|c|c|c|c|c|c|}
\hline Cuba & $57 \%$ & 0.0 & 63 & $54 \%$ & 0.0 & 60 \\
\hline Guyana & $57 \%$ & 4.8 & 969 & $54 \%$ & 4.6 & 923 \\
\hline Honduras & $57 \%$ & 1.7 & 6,710 & $54 \%$ & 1.6 & 6,386 \\
\hline Bolivia & $57 \%$ & 2.6 & 12,692 & $54 \%$ & 2.5 & 12,080 \\
\hline Haiti & $57 \%$ & 5.2 & 26,275 & $35 \%$ & 3.2 & 16,098 \\
\hline Nicaragua & $57 \%$ & 1.2 & 3,384 & $54 \%$ & 1.1 & 3,195 \\
\hline \multicolumn{7}{|l|}{ EMR D } \\
\hline Afghanistan & $53 \%$ & 12.5 & 254,469 & $35 \%$ & 8.2 & 166,606 \\
\hline Djibouti & $53 \%$ & 5.4 & 2,234 & $35 \%$ & 3.5 & 1,463 \\
\hline Pakistan & $53 \%$ & 3.5 & 315,915 & $35 \%$ & 2.3 & 206,836 \\
\hline Somalia & $55 \%$ & 12.1 & 78,642 & $35 \%$ & 7.7 & 49,641 \\
\hline Sudan & $53 \%$ & 2.9 & 65,913 & $35 \%$ & 1.9 & 43,155 \\
\hline Yemen & $53 \%$ & 4.0 & 67,530 & $35 \%$ & 2.6 & 44,213 \\
\hline \multicolumn{7}{|l|}{ EUR B \& C } \\
\hline Armenia & $59 \%$ & 1.1 & 907 & $54 \%$ & 1.0 & 834 \\
\hline Azerbaijan & $59 \%$ & 4.7 & 14,086 & $35 \%$ & 2.8 & 8,329 \\
\hline Georgia & $59 \%$ & 1.7 & 1,471 & $54 \%$ & 1.6 & 1,352 \\
\hline Kyrgyzstan & $59 \%$ & 3.3 & 7,922 & $54 \%$ & 3.1 & 7,277 \\
\hline Tajikistan & $59 \%$ & 7.1 & 24,217 & $54 \%$ & 6.5 & 22,246 \\
\hline Uzbekistan & $59 \%$ & 3.6 & 41,188 & $54 \%$ & 3.3 & 37,836 \\
\hline Moldova & $59 \%$ & 0.2 & 159 & $54 \%$ & 0.2 & 146 \\
\hline Ukraine & $59 \%$ & 0.1 & 590 & $54 \%$ & 0.1 & 542 \\
\hline \multicolumn{7}{|l|}{ SEAR B \& D } \\
\hline Indonesia & $57 \%$ & 2.3 & 187,993 & $54 \%$ & 2.2 & 176,588 \\
\hline Korea, Democratic Republic & $57 \%$ & 2.1 & 12,982 & $54 \%$ & 2.0 & 12,194 \\
\hline Sri Lanka & $57 \%$ & 0.6 & 3,424 & $54 \%$ & 0.6 & 3,216 \\
\hline Timor Leste & $57 \%$ & 4.3 & 4,470 & $54 \%$ & 4.1 & 4,199 \\
\hline Bangladesh & $55 \%$ & 3.4 & 231,585 & $54 \%$ & 3.3 & 225,739 \\
\hline Bhutan & $57 \%$ & 3.8 & 858 & $54 \%$ & 3.6 & 806 \\
\hline India & $53 \%$ & 3.6 & $1,777,110$ & $54 \%$ & 3.7 & $1,802,809$ \\
\hline Myanmar & $57 \%$ & 4.9 & 79,028 & $35 \%$ & 3.0 & 47,784 \\
\hline Nepal & $58 \%$ & 3.5 & 52,750 & $54 \%$ & 3.2 & 48,998 \\
\hline \multicolumn{7}{|l|}{ WPR B } \\
\hline Cambodia & $57 \%$ & 8.6 & 63,250 & $35 \%$ & 5.2 & 38,244 \\
\hline Kiribati & $57 \%$ & 4.9 & 118 & $54 \%$ & 4.6 & 111 \\
\hline Lao People Democratic Republic & $57 \%$ & 4.6 & 14,067 & $54 \%$ & 4.3 & 13,213 \\
\hline Mongolia & $57 \%$ & 2.6 & 2,316 & $54 \%$ & 2.5 & 2,176 \\
\hline Papua New Guinea & $57 \%$ & 5.0 & 16,493 & $54 \%$ & 4.7 & 15,492 \\
\hline Solomon Islands & $57 \%$ & 1.7 & 493 & $54 \%$ & 1.6 & 463 \\
\hline Viet Nam & $58 \%$ & 0.8 & 26,089 & $54 \%$ & 0.8 & 24,032 \\
\hline
\end{tabular}

I\$ = International dollars; DALY = Disability-adjusted life year; ICER = Incremental cost-effectiveness ratio.

AFR = African Region; EMR = Eastern Mediterranean Region; EUR = European Region; AMR = Region of the Americas; WPR = Western Pacific Region; SEAR = South-East Asian Region. 

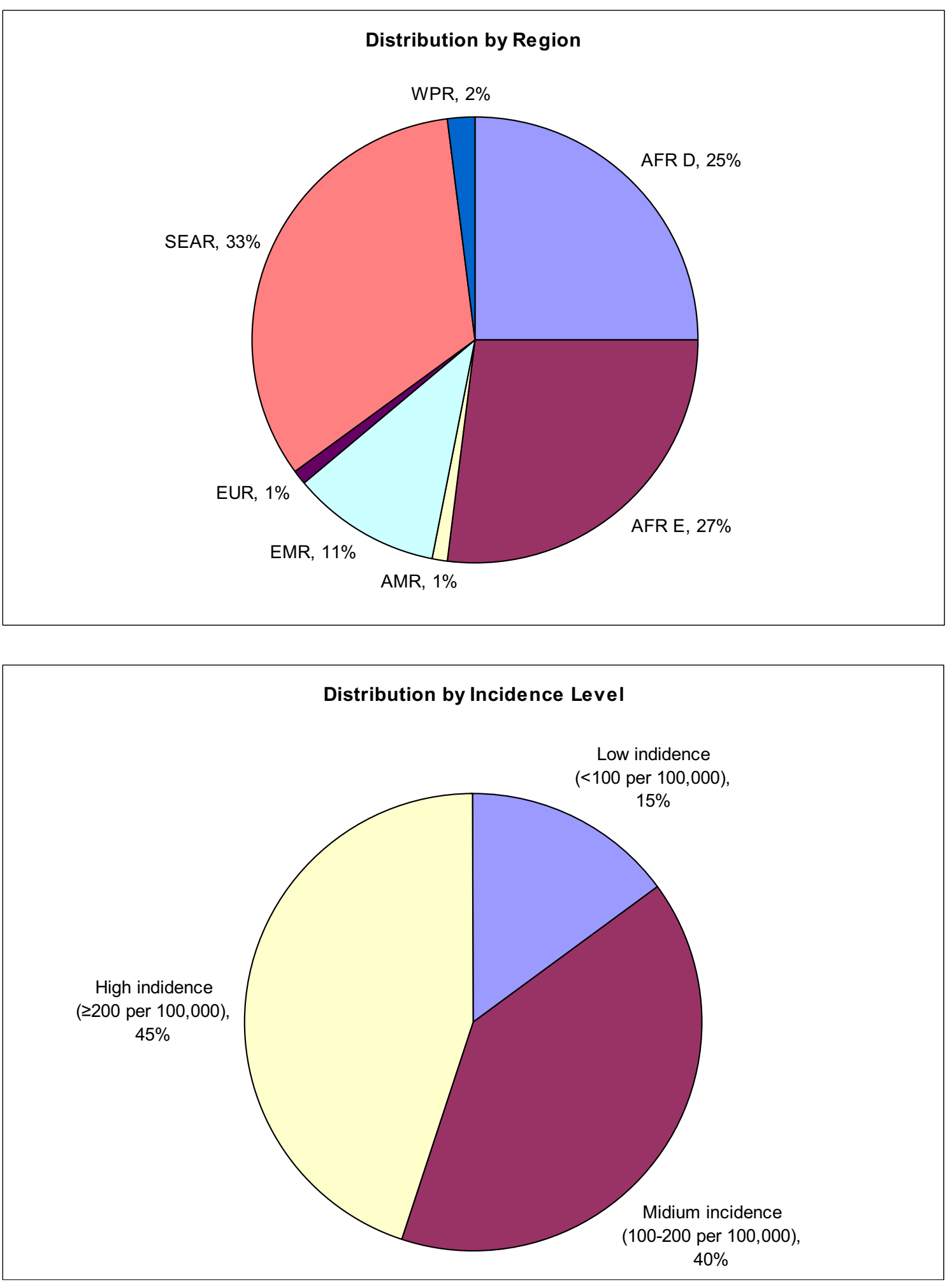

Figure 2 Distribution of averted rotavirus disease burden (DALYs) in the GAVI-eligible countries. Upper panel shows the distribution of averted DALYs associated with rotavirus infection by region. Lower panel shows the corresponding distribution by the level of rotavirus mortality burden (among children under age 5). 
Table 4: Cost-effectiveness of rotavirus vaccination in the GAVI-eligible countries

\begin{tabular}{|c|c|c|c|c|c|c|}
\hline \multirow[t]{2}{*}{ Country } & \multicolumn{3}{|c|}{$\begin{array}{c}\text { Base-case vaccine efficacy (adjusted for serotype } \\
\text { distribution) }\end{array}$} & \multicolumn{3}{|c|}{ Vaccine efficacy based on SAGE recommendation } \\
\hline & $\begin{array}{r}\text { ICERa }(\mathbf{I \$} / \mathrm{DALY} \\
\text { averted) I\$10 } \\
\text { per vaccinated } \\
\text { child }\end{array}$ & $\begin{array}{r}\text { ICERa }(\mathbf{I \$ / D A L Y} \\
\text { averted) I\$25 } \\
\text { per vaccinated } \\
\text { child }\end{array}$ & $\begin{array}{r}\text { ICER }^{\mathrm{b}}(\mathrm{IS} / \mathrm{DALY} \\
\text { averted) based } \\
\text { on GAVI's co- } \\
\text { financing } \\
\text { scheme }\end{array}$ & $\begin{array}{r}\text { ICERa }^{(\text {I\$ } / D A L Y} \\
\text { averted) I\$10 } \\
\text { per vaccinated } \\
\text { child }\end{array}$ & $\begin{array}{r}\text { ICER }^{\mathrm{a}}(\mathbf{I} / \mathrm{DALY} \\
\text { averted) I\$25 } \\
\text { per vaccinated } \\
\text { child }\end{array}$ & $\begin{array}{r}\text { ICER }^{\mathbf{b}}(\mathrm{IS} / \mathrm{DALY} \\
\text { averted) based } \\
\text { on GAVI's co- } \\
\text { financing } \\
\text { scheme }\end{array}$ \\
\hline \multicolumn{7}{|l|}{ AFR D } \\
\hline Angola & saving & 26 & 4 & 0.2 & 68 & 22 \\
\hline Benin & 25 & 108 & 52 & 57 & 190 & 87 \\
\hline Burkina Faso & 22 & 90 & 37 & 42 & 141 & 59 \\
\hline Cameroon & 22 & 108 & 57 & 54 & 190 & 93 \\
\hline Chad & saving & 54 & 33 & 17 & 113 & 59 \\
\hline Comoros & 119 & 341 & 150 & 122 & 348 & 153 \\
\hline Ghana & 71 & 221 & 100 & 142 & 398 & 176 \\
\hline Guinea & 18 & 99 & 54 & 49 & 178 & 88 \\
\hline Guinea-Bissau & 7 & 68 & 37 & 26 & 113 & 57 \\
\hline Liberia & 17 & 67 & 32 & 37 & 114 & 53 \\
\hline Madagascar & 20 & 124 & 65 & 60 & 225 & 108 \\
\hline Mali & 5 & 58 & 29 & 26 & 109 & 51 \\
\hline Mauritania & 21 & 116 & 52 & 58 & 209 & 92 \\
\hline Niger & saving & 36 & 23 & 10 & 78 & 42 \\
\hline Nigeria & 27 & 102 & 48 & 51 & 162 & 74 \\
\hline Sao Thome & 40 & 152 & 65 & 83 & 262 & 112 \\
\hline Senegal & 32 & 125 & 56 & 68 & 215 & 95 \\
\hline Sierra Leone & 2 & 41 & 21 & 17 & 79 & 37 \\
\hline The Gambia & 59 & 196 & 87 & 112 & 328 & 145 \\
\hline Togo & 46 & 155 & 75 & 88 & 262 & 121 \\
\hline \multicolumn{7}{|l|}{ AFRE } \\
\hline Burundi & 22 & 84 & 44 & 46 & 145 & 70 \\
\hline $\begin{array}{l}\text { Central African } \\
\text { Republic }\end{array}$ & 20 & 96 & 46 & 50 & 171 & 78 \\
\hline Congo & 74 & 250 & 111 & 143 & 422 & 185 \\
\hline Cote d'Ivoire & 21 & 95 & 47 & 44 & 153 & 72 \\
\hline $\begin{array}{l}\text { Democratic } \\
\text { Republic of the } \\
\text { Congo }\end{array}$ & 19 & 76 & 39 & 41 & 131 & 62 \\
\hline Eritrea & 95 & 266 & 117 & 97 & 272 & 120 \\
\hline Ethiopia & 28 & 98 & 45 & 55 & 166 & 74 \\
\hline Kenya & 37 & 150 & 68 & 81 & 260 & 115 \\
\hline Lesotho & 397 & 1,061 & 459 & 655 & 1,707 & 737 \\
\hline Malawi & 26 & 93 & 40 & 55 & 165 & 71 \\
\hline Mozambique & 31 & 115 & 48 & 64 & 198 & 83 \\
\hline Rwanda & 1 & 58 & 30 & 23 & 114 & 54 \\
\hline Tanzania & 42 & 147 & 66 & 87 & 258 & 114 \\
\hline Uganda & 31 & 127 & 62 & 68 & 220 & 102 \\
\hline
\end{tabular}


Table 4: Cost-effectiveness of rotavirus vaccination in the GAVI-eligible countries (Continued)

\begin{tabular}{|c|c|c|c|c|c|c|}
\hline Zambia & 23 & 103 & 45 & 49 & 166 & 72 \\
\hline Zimbabwe & 78 & 251 & 110 & 134 & 391 & 170 \\
\hline \multicolumn{7}{|l|}{ AMR A, B \& D } \\
\hline Cuba & 11,332 & 28,443 & 12,240 & 11,909 & 29,888 & 12,862 \\
\hline Guyana & 4 & 113 & 40 & 7 & 122 & 44 \\
\hline Honduras & 85 & 386 & 190 & 95 & 411 & 201 \\
\hline Bolivia & 47 & 246 & 120 & 53 & 262 & 128 \\
\hline Haiti & 4 & 105 & 56 & 46 & 212 & 102 \\
\hline Nicaragua & 217 & 646 & 289 & 234 & 688 & 307 \\
\hline \multicolumn{7}{|l|}{ EMR D } \\
\hline Afghanistan & saving & 47 & 29 & 15 & 90 & 48 \\
\hline Djibouti & saving & 90 & 54 & 25 & 179 & 92 \\
\hline Pakistan & 42 & 192 & 102 & 95 & 325 & 159 \\
\hline Somalia & saving & 39 & 32 & 11 & 83 & 51 \\
\hline Sudan & 84 & 266 & 121 & 148 & 426 & 190 \\
\hline Yemen & 26 & 160 & 82 & 73 & 276 & 132 \\
\hline \multicolumn{7}{|l|}{ EUR B \& C } \\
\hline Armenia & 227 & 685 & 312 & 254 & 753 & 341 \\
\hline Azerbaijan & saving & 95 & 68 & 35 & 223 & 123 \\
\hline Georgia & 131 & 429 & 206 & 148 & 473 & 225 \\
\hline Kyrgyzstan & 59 & 215 & 99 & 68 & 239 & 109 \\
\hline Tajikistan & 6 & 80 & 48 & 10 & 91 & 53 \\
\hline Uzbekistan & saving & 122 & 58 & saving & 144 & 67 \\
\hline Moldova & 1,763 & 4,497 & 1,949 & 1,925 & 4,900 & 2,122 \\
\hline Ukraine & 4,816 & 12,161 & 5,243 & 5,249 & 13,245 & 5,710 \\
\hline \multicolumn{7}{|l|}{ SEAR B \& D } \\
\hline Indonesia & 80 & 302 & 136 & 90 & 326 & 146 \\
\hline $\begin{array}{l}\text { Korea, } \\
\text { Democratic } \\
\text { Republic }\end{array}$ & 118 & 363 & 154 & 129 & 390 & 165 \\
\hline Sri Lanka & 487 & 1,303 & 565 & 522 & 1,391 & 603 \\
\hline Timor Leste & 41 & 161 & 67 & 46 & 174 & 73 \\
\hline Bangladesh & 50 & 209 & 104 & 52 & 216 & 106 \\
\hline Bhutan & 38 & 175 & 75 & 44 & 190 & 81 \\
\hline India & 54 & 201 & 97 & 53 & 198 & 96 \\
\hline Myanmar & 28 & 137 & 74 & 75 & 256 & 126 \\
\hline Nepal & 62 & 215 & 102 & 70 & 235 & 110 \\
\hline \multicolumn{7}{|l|}{ WPR B } \\
\hline Cambodia & saving & 44 & 34 & 10 & 111 & 63 \\
\hline Kiribati & 4 & 111 & 50 & 9 & 122 & 54 \\
\hline $\begin{array}{l}\text { Lao People } \\
\text { Democratic } \\
\text { Republic }\end{array}$ & 15 & 132 & 77 & 20 & 144 & 83 \\
\hline Mongolia & 77 & 274 & 114 & 85 & 296 & 123 \\
\hline $\begin{array}{l}\text { Papua New } \\
\text { Guinea }\end{array}$ & saving & 84 & 36 & saving & 95 & 41 \\
\hline
\end{tabular}


Table 4: Cost-effectiveness of rotavirus vaccination in the GAVI-eligible countries (Continued)

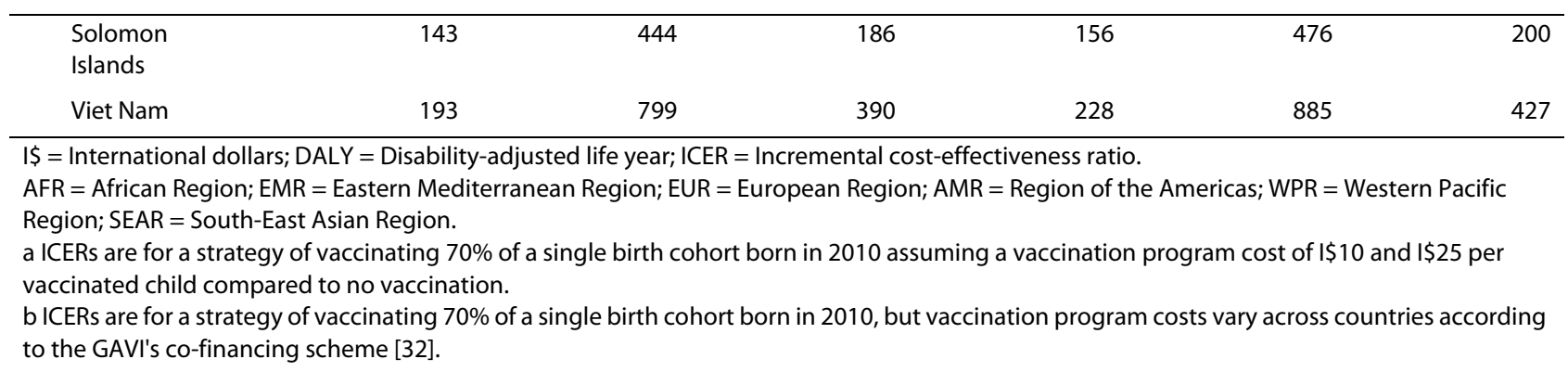

country- or region-specific serotype distribution and serotype-specific vaccine efficacy. Accordingly, rotavirus vaccination appeared less cost-effective; for instance, assuming this alternate efficacy and $\mathbf{I} 25$ per vaccinated child, only seven countries had an incremental cost per DALY averted under I\$100 (Table 4).

\section{Budget impact: Forecasting disease burden reduction and financial costs}

Table 5 summarizes the impact of alternative scale-up scenarios (combined with different vaccine efficacy estimates) on the overall disease burden reduction aggregated across the GAVI countries over a 10-year period. The first four rows in Table 5 present the results based on the base-case rollout scenarios. The results from the first scenario (assuming the base-case rollout scenario, vaccine efficacy based on the SAGE approach, and vaccine immunity waning) show that a 10-year effort for rotavirus vaccine scale-up would prevent about 41 million cases of outpatient visits, 4.5 million hospitalizations, and 0.9 million deaths caused by rotavirus in the GAVI countries. Without assuming immunity waning, the second scenario projects higher levels $(\sim 10 \%)$ of reduction in disease burden. The other alternative scenarios combined with different assumptions show very similar patterns. Similarly, Table 6 shows the aggregate financial requirements in the GAVI countries using the same set of scale-up scenarios. Figure 3 presents the incremental budget impact for each year of the 10-year time horizon, using Djibouti as an example. In our base-case rollout scenario, the country is assumed to provide rotavirus vaccines starting in 2011 (Table 2), achieve full coverage (89\%) in 2015, and maintain full coverage for the rest of the time horizon. For each year, the left-hand bars in the graph indicate the financial costs of sustaining a rotavirus program without considering the savings to the government from averted treatment costs, while the right-hand bars indicate the financial costs when including such savings. (See Additional file 1 for country-specific results not considering the savings to the government.)

\section{Discussion}

While child mortality is reported to have decreased in general since 1990, mortality among young children remains high in many developing countries. The most recent World Health Statistics show that diarrhea makes up the second or third cause of childhood deaths in most low-income countries [22]; in 68 of the 72 GAVI-countries, diarrhea accounts for more than $10 \%$ of deaths among young children. Since rotavirus is the most common cause of severe gastroenteritis among young children, any interventions to control rotavirus infection have the potential to greatly improve childhood mortality, contributing to achieving one of the MDG targets.

Our findings show that routine infant vaccination using either of the two new recent vaccines would prevent 0.9 2.8 million deaths associated with rotavirus infection among children under age 5 in the poorest parts of the world over the next decade (2010-2019), depending on vaccine scale-up scenarios. Rotavirus vaccination programs would also prevent 4.5-13.3 million estimated cases of hospitalization and 41-107 million cases of outpatient clinic visits in the same population over the same intervention period.

Our results also show that rotavirus vaccine programs would be considered a cost-effective public health intervention in most GAVI countries; using the WHO's costeffectiveness threshold based on per capita GDP, the vaccines were considered cost-effective in 68 of the 72 countries $(\sim 94 \%)$. It should be noted that a rotavirus vaccination program might not prove cost-effective in countries with a relatively low rotavirus mortality rate like Cuba, Ukraine, and Moldova. Although the likelihood that a country will introduce a new vaccine or scaleup rate is not always proportionate to the level of disease burden, these results may affect policy makers' decisions whether or not to introduce a vaccine. For example, although Cuba is classified into a high demand region in a previous study [36] and in the present study, Cuba's rotavirus associated mortality rate is less than 1 per 100,000 children under age 5 and estimated incremental costeffectiveness is about I $\$ 30,000$ per DALY averted (at the 
Table 5: Health impact of alternative scale-up scenarios in the GAVI-eligible countries

\begin{tabular}{|c|c|c|c|c|c|c|c|}
\hline No & Scale-up scenarios & $\begin{array}{l}\text { No. of children } \\
\text { vaccinated } \\
\text { (in million) }\end{array}$ & $\begin{array}{c}\text { No. of } \\
\text { outpatient } \\
\text { visits averted } \\
\text { (r=0\%) (in } \\
\text { million) }\end{array}$ & $\begin{array}{c}\text { No. of } \\
\text { hospitalizatio } \\
n \text { averted } \\
(r=0 \%) \text { (in } \\
\text { million) }\end{array}$ & $\begin{array}{l}\text { No. of deaths } \\
\text { averted } \\
(r=0 \%) \text { (in } \\
\text { million) }\end{array}$ & $\begin{array}{c}\text { YL saved } \\
(r=3 \%) \text { (in } \\
\text { million) }\end{array}$ & $\begin{array}{c}\text { DALYs averted } \\
\text { ( } r=3 \%) \text { (in } \\
\text { million) }\end{array}$ \\
\hline \multirow[t]{3}{*}{1} & $\begin{array}{l}\text { Base-case rollout scenario } \\
\text { (Table 2) }\end{array}$ & & & & & & \\
\hline & $\begin{array}{l}\text { Vaccine efficacy based on } \\
\text { the SAGE approach }\end{array}$ & & & & & & \\
\hline & $\begin{array}{l}\text { Vaccine immunity waning } \\
\text { (14\% annually) }\end{array}$ & 281.8 & 40.7 & 4.5 & 0.9 & 20.3 & 20.4 \\
\hline \multirow[t]{3}{*}{2} & $\begin{array}{l}\text { Base-case rollout scenario } \\
\text { (Table 2) }\end{array}$ & & & & & & \\
\hline & $\begin{array}{l}\text { Vaccine efficacy based on } \\
\text { the SAGE approach }\end{array}$ & & & & & & \\
\hline & $\begin{array}{l}\text { No vaccine immunity } \\
\text { waning }\end{array}$ & 281.8 & 44.1 & 4.9 & 1.0 & 22.0 & 22.1 \\
\hline \multirow[t]{3}{*}{3} & $\begin{array}{l}\text { Base-case rollout scenario } \\
\text { (Table 2) }\end{array}$ & & & & & & \\
\hline & $\begin{array}{l}\text { Vaccine efficacy adjusted } \\
\text { for serotype distribution }\end{array}$ & & & & & & \\
\hline & $\begin{array}{l}\text { Vaccine immunity waning } \\
\text { (14\% annually) }\end{array}$ & 281.8 & 47.8 & 5.6 & 1.2 & 25.3 & 25.4 \\
\hline \multirow[t]{3}{*}{$4^{a}$} & $\begin{array}{l}\text { Base-case rollout scenario } \\
\text { (Table 2) }\end{array}$ & & & & & & \\
\hline & $\begin{array}{l}\text { Vaccine efficacy adjusted } \\
\text { for serotype distribution }\end{array}$ & & & & & & \\
\hline & $\begin{array}{l}\text { No vaccine immunity } \\
\text { waning }\end{array}$ & 281.8 & 51.7 & 6.0 & 1.3 & 27.3 & 27.4 \\
\hline \multirow[t]{3}{*}{5} & $\begin{array}{l}\text { (Modified) Wolfson et al. } \\
\text { scenario [37] }\end{array}$ & & & & & & \\
\hline & $\begin{array}{l}\text { Vaccine efficacy based on } \\
\text { the SAGE approach }\end{array}$ & & & & & & \\
\hline & $\begin{array}{l}\text { No vaccine immunity } \\
\text { waning }\end{array}$ & 410.5 & 64.2 & 7.7 & 1.6 & 35.6 & 35.7 \\
\hline \multirow[t]{3}{*}{6} & $\begin{array}{l}\text { (Modified) Wolfson et al. } \\
\text { scenario [37] }\end{array}$ & & & & & & \\
\hline & $\begin{array}{l}\text { Vaccine efficacy adjusted } \\
\text { for serotype distribution }\end{array}$ & & & & & & \\
\hline & $\begin{array}{l}\text { No vaccine immunity } \\
\text { waning }\end{array}$ & 410.5 & 81.4 & 10.4 & 2.2 & 48.1 & 48.3 \\
\hline \multirow[t]{3}{*}{7} & A flat coverage of $70 \%$ & & & & & & \\
\hline & $\begin{array}{l}\text { Vaccine efficacy based on } \\
\text { the SAGE approach }\end{array}$ & & & & & & \\
\hline & $\begin{array}{l}\text { No vaccine immunity } \\
\text { waning }\end{array}$ & 537.0 & 85.9 & 10.1 & 2.1 & 48.9 & 49.1 \\
\hline
\end{tabular}


Table 5: Health impact of alternative scale-up scenarios in the GAVI-eligible countries (Continued)

\begin{tabular}{|c|c|c|c|c|c|c|c|}
\hline \multirow[t]{3}{*}{8} & \multicolumn{7}{|l|}{ A flat coverage of $70 \%$} \\
\hline & \multicolumn{7}{|l|}{$\begin{array}{l}\text { Vaccine efficacy adjusted } \\
\text { for serotype distribution }\end{array}$} \\
\hline & $\begin{array}{l}\text { No vaccine immunity } \\
\text { waning }\end{array}$ & 537.0 & 106.6 & 13.3 & 2.8 & 64.5 & 64.7 \\
\hline
\end{tabular}

Table 6: Budget impact of alternative scale-up scenarios in the GAVI-eligible countries

\begin{tabular}{|c|c|c|c|c|c|c|}
\hline \multirow[b]{2}{*}{ No } & \multirow[b]{2}{*}{ Scale-up scenarios } & \multirow[b]{2}{*}{$\begin{array}{l}\text { No. of children } \\
\text { vaccinated }\end{array}$} & \multicolumn{4}{|c|}{ Financial costs $^{a}$} \\
\hline & & & $\begin{array}{l}\text { Global society } \\
\text { perspective } \\
\text { (Total } \\
\text { vaccination } \\
\text { program costs) } \\
\text { (US\$, million) }\end{array}$ & $\begin{array}{l}\text { GAVI Alliance } \\
\text { perspective } \\
\text { (Vaccine cost } \\
\text { support) } \\
\text { (US\$, million) }\end{array}$ & $\begin{array}{c}\text { Local } \\
\text { government } \\
\text { perspective (not } \\
\text { including } \\
\text { medical cost } \\
\text { savings) } \\
\text { (US\$, million) }\end{array}$ & $\begin{array}{l}\text { Local } \\
\text { government } \\
\text { perspective } \\
\text { (including } \\
\text { medical cost } \\
\text { savings) }^{\mathbf{b}} \\
\text { (US\$, million) }^{\text {(US, }}\end{array}$ \\
\hline \multirow[t]{3}{*}{1} & $\begin{array}{l}\text { Base-case rollout scenario } \\
\text { (Table } 2 \text { ) }\end{array}$ & & & & & \\
\hline & $\begin{array}{l}\text { Vaccine efficacy based on the } \\
\text { SAGE approach }\end{array}$ & & & & & \\
\hline & $\begin{array}{l}\text { Vaccine immunity waning } \\
\text { (14\% annually) }\end{array}$ & 281.8 & 5,879 & 4,079 & 1,800 & 1,714 \\
\hline \multirow[t]{3}{*}{2} & $\begin{array}{l}\text { Base-case rollout scenario } \\
\text { (Table } 2 \text { ) }\end{array}$ & & & & & \\
\hline & $\begin{array}{l}\text { Vaccine efficacy based on the } \\
\text { SAGE approach }\end{array}$ & & & & & \\
\hline & No vaccine immunity waning & 281.8 & 5,879 & 4,079 & 1,800 & 1,707 \\
\hline \multirow[t]{3}{*}{3} & $\begin{array}{l}\text { Base-case rollout scenario } \\
\text { (Table } 2 \text { ) }\end{array}$ & & & & & \\
\hline & $\begin{array}{l}\text { Vaccine efficacy adjusted for } \\
\text { serotype distribution }\end{array}$ & & & & & \\
\hline & $\begin{array}{l}\text { Vaccine immunity waning } \\
\text { (14\% annually) }\end{array}$ & 281.8 & 5,879 & 4,079 & 1,800 & 1,695 \\
\hline \multirow[t]{3}{*}{$4^{c}$} & $\begin{array}{l}\text { Base-case rollout scenario } \\
\text { (Table } 2 \text { ) }\end{array}$ & & & & & \\
\hline & $\begin{array}{l}\text { Vaccine efficacy adjusted for } \\
\text { serotype distribution }\end{array}$ & & & & & \\
\hline & No vaccine immunity waning & 281.8 & 5,879 & 4,079 & 1,800 & 1,686 \\
\hline \multirow[t]{3}{*}{5} & $\begin{array}{l}\text { (Modified) Wolfson et al. } \\
\text { scenario [30] }\end{array}$ & & & & & \\
\hline & $\begin{array}{l}\text { Vaccine efficacy based on the } \\
\text { SAGE approach }\end{array}$ & & & & & \\
\hline & No vaccine immunity waning & 410.5 & 8,573 & 5,943 & 2,630 & 2,472 \\
\hline
\end{tabular}


Table 6: Budget impact of alternative scale-up scenarios in the GAVI-eligible countries (Continued)

\begin{tabular}{|c|c|c|c|c|c|c|}
\hline \multirow[t]{3}{*}{6} & $\begin{array}{l}\text { (Modified) Wolfson et al. } \\
\text { scenario [30] }\end{array}$ & \multirow[b]{3}{*}{410.5} & \multirow[b]{3}{*}{8,573} & \multirow[b]{3}{*}{5,943} & \multirow[b]{3}{*}{2,630} & \multirow[b]{3}{*}{2,414} \\
\hline & $\begin{array}{l}\text { Vaccine efficacy adjusted for } \\
\text { serotype distribution }\end{array}$ & & & & & \\
\hline & No vaccine immunity waning & & & & & \\
\hline \multirow[t]{3}{*}{7} & A flat coverage of $70 \%$ & & & & & \\
\hline & $\begin{array}{l}\text { Vaccine efficacy based on the } \\
\text { SAGE approach }\end{array}$ & & & & & \\
\hline & No vaccine immunity waning & 537.0 & 11,222 & 7,785 & 3,437 & 3,236 \\
\hline \multirow[t]{3}{*}{8} & A flat coverage of $70 \%$ & & & & & \\
\hline & $\begin{array}{l}\text { Vaccine efficacy adjusted for } \\
\text { serotype distribution }\end{array}$ & & & & & \\
\hline & No vaccine immunity waning & 537.0 & 11,222 & 7,785 & 3,437 & 3,170 \\
\hline \multicolumn{7}{|c|}{$\begin{array}{l}r=\text { discount rate; } Y L=\text { years of life; DALYs = disability-adjusted life-years; I\$ = international do } \\
\text { on Immunization. } \\
\text { a All 10-year forecasts are based on the composite program cost of I\$25 (corresponding to US } \\
\text { not discounted. } \\
\text { b The vaccine costs to local governments are based on the GAVI's co-financing scheme [32]. } \\
\text { c Base-case analysis. }\end{array}$} \\
\hline
\end{tabular}

composite vaccination cost of I $\$ 25$ per vaccinated child). It is conceivable that policy makers might want to consider using resources to introduce other childhood vaccines or to extend coverage of existing health interventions that target a higher burden of disease.

In the present analysis, the most influential factor in the cost-effectiveness results was per child vaccination costs, which includes rotavirus vaccine costs, vaccine wastage, and any activities to support the delivery of the vaccines. Since the data on country-specific incremental costs for introducing a new childhood vaccine into a national immunization program are rarely available for lowincome countries, we chose to use a composite cost approach, assuming a total program cost of I\$10 or I\$25 per vaccinated child. Accordingly, our base-case costeffectiveness results use standardized vaccination program costs across the 72 GAVI countries, so the main differences in the incremental cost-effectiveness ratios may be attributable to the differences in disease burden (i.e., rotavirus associated mortality rates, ratios of rotavirus associated hospitalizations or outpatient visits to rotavirus deaths) and vaccine efficacy adjusted for serotype distributions. Note that, although the discount rate was still relatively influential, it was not as important as it is with vaccines where benefits are realized in the distant future (e.g., HPV or HBV vaccines). The results were robust to country-specific hourly wage rates or transportation costs per medical visit, which were used in calculating direct non-medical costs such as caregivers' time costs or travel costs. The results were not sensitive to assumptions about medical utilization such as average length of hospitalization or average time spent per outpatient clinic visit.

Note that our base-case estimates of the main health outcome (i.e. DALYs averted) are based on uniform age weights $(K=0)$, primarily for normative reasons, while a majority of previous similar studies use the standard age weights $(K=1)$ used by the WHO GBD study [19]. Uniform age weighting leads to relatively lower years of life lost (YLL) compared with those associated with standard age weighting $(\mathrm{K}=1)$ over the age range of age $0-4$ years [20]. Accordingly, when assuming similar model structure and parameter values, our results are more conservative since our base-case analysis $(K=0)$ yields a lower number of DALYs averted than other similar studies that evaluate the impact of rotavirus vaccination in terms of DALYs incorporating non-uniform age weights $(K=1)$ (as also shown in the sensitivity analysis results).

Although the WHO SAGE recommended global use of rotavirus vaccines based on the evidence from recent clinical trials, there is a high level of uncertainty about short-term and longer-term vaccine efficacy in local settings given the variability of rotavirus serotype distributions across regions and over time. Our analysis shows the implication of following SAGE's recommendation to transfer vaccine efficacy by using data from other countries with comparable levels of childhood mortality. In a majority of the GAVI countries, the extended vaccine efficacy following the SAGE approach was lower than the weighted average of serotype-specific vaccine efficacy used in our base-case analysis. Correspondingly, the 


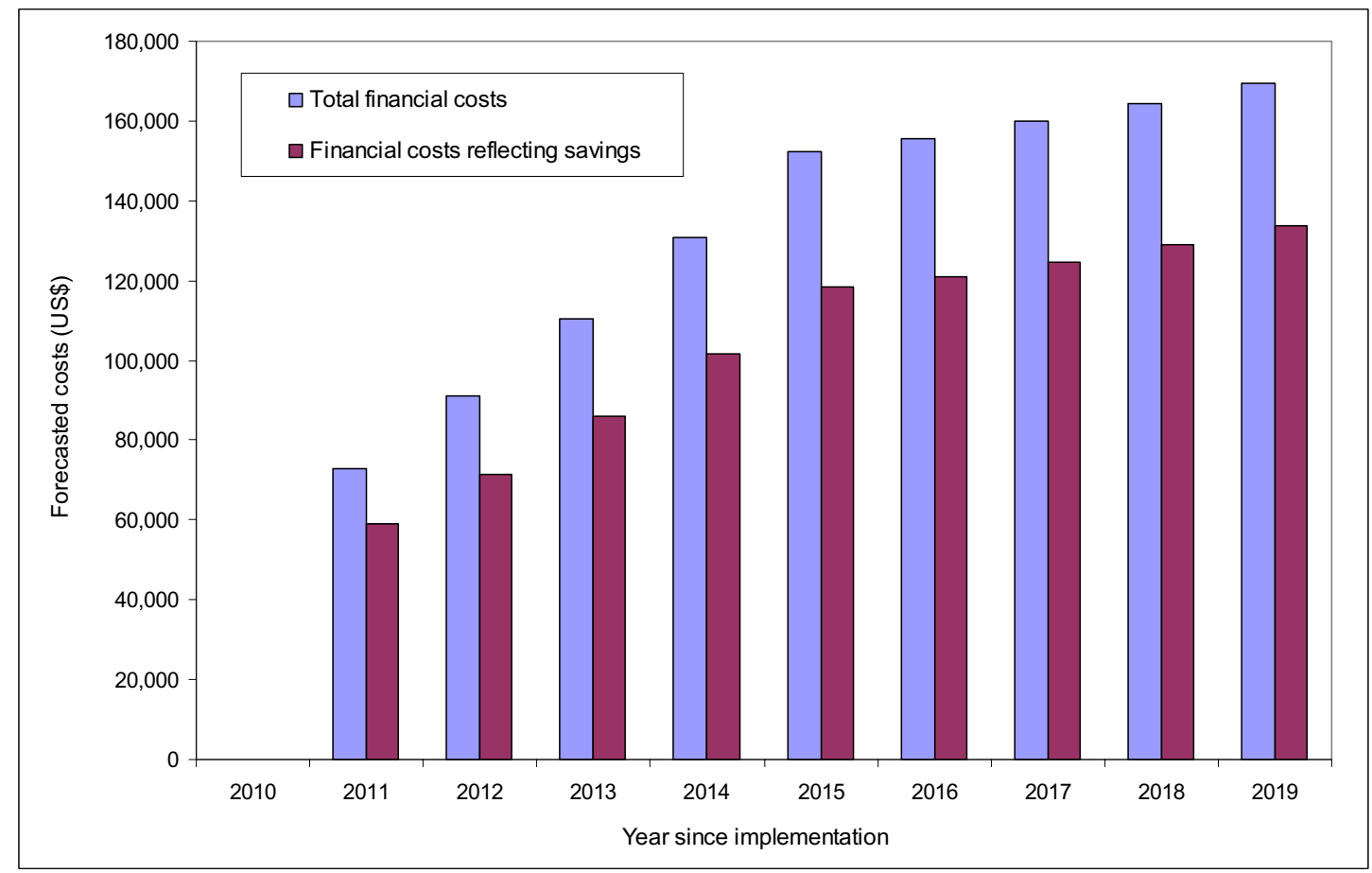

Figure 3 Budget impact of rotavirus vaccination in Djibouti. This figure shows the budget impact of a rotavirus program in Djibouti for each year of a 10-year time horizon. For each year, the difference between the bars indicates the savings to the government from averted treatment costs.

results of a secondary analysis using the SAGE approach showed the estimated avertable burden to be about $30 \%$ (0-70\%) lower.

Recently an increasing number of published studies have evaluated the health and economic consequences of rotavirus vaccines in different settings, using various modeling approaches $[16,25,26,36,39-59]$. Ten studies $[16,25,36,39-44,52]$ have assessed cost-effectiveness of rotavirus vaccination in low-income countries. When subject to the same currency type, inflation and vaccine price, our results were comparable to those from the studies performed in low-income country settings. For example, when we roughly adjusted Rose et al.'s results for India that are obtained using an individual-level Markov model [39] for currency type and inflation, the adjusted incremental cost-effectiveness ratio of $\sim \mathrm{I} \$ 140$ per DALY averted was comparable to our result for India, I\$200 per DALY averted (at I\$25 per vaccinated child). When we assumed similar program costs, the discrepancy in the two studies' results was further reduced.

The cost-effectiveness profiles of rotavirus vaccines from the present study are also very similar to those for HPV vaccines reported in a previous study [60], which was performed using a similar approach in the 72 GAVIeligible countries. That study reported that at a cost per vaccinated girl of I\$10 (\$2 per dose), for 49 of 72 countries, the cost per DALY averted was less than I\$100 (or the program was cost-saving), and for an additional 12 countries, less than I $\$ 200$. At higher costs per vaccinated girl (e.g. I\$25), for 33 of 72 countries, the cost per DALY averted was less than I\$300, and for an additional 23 countries, less than I $\$ 500$ [60]. However, provided vaccine prices are similar, the financial resources required are very different, in large part due to differences in the size of the target populations (i.e., infants of both genders versus adolescent girls). Interestingly, although not immediately intuitive, the avertable mortality burden from the two vaccines is also similar. For example, while annual deaths among the 72 GAVI countries are estimated to be $\sim 466,000$ from rotavirus [29] and $\sim 161,000$ from cervical cancer [61], if we restrict the comparison to female gender, the annual deaths are $\sim 230,000$ versus $\sim 161,000$. Further, these estimates represent deaths based on a snapshot of a population structure for a particular calendar year, and do not reflect a future population dynamics. Consider the present day (2010) cohort of newborn infants and the present day cohort of 9-year old girls (2010) in the GAVI-eligible countries. Modeled projections show approximately 508,000 of the infants will die from rotavirus and 580,000 of the 9-year old girls will 
eventually die from cervical cancer. Clearly both vaccines are priorities.

Although a rotavirus program proves cost-effective over a wide range of parameter values and alternative assumptions, countries need information on affordability of the vaccines as well. That is, in most low-income countries with severe resource constraints, multiple public health priorities compete for a limited shared budget; policy makers need to know the financial costs required to implement any program as well as its value for money. In the present study, in addition to the secondary costeffectiveness analysis from the local government perspective, we performed a budget impact analysis based on simplifying assumptions, taking into account the 'new vaccine co-financing policy' recently announced by the GAVI Alliance, in order to project financial requirements and potential savings from averted medical costs for each year of the 10-year period. Our findings suggest that, with GAVI's support, the costs to each GAVI country would be reduced to approximately I\$10-I $\$ 11$ when assuming a composite program cost of $\mathrm{I} \$ 25$, but that covering this would still be a substantial burden to the lowest-income GAVI countries. This type of analysis may be useful to policy makers seeking to address the question of affordability of new vaccines by comparing the budget impact forecast with their own projected total immunization budget. Assessment of affordability is not complicated when there is a single earmarked budget for a new vaccine of interest. However, if there are multiple other immunization (or public health) programs competing for a shared budget, choosing an optimal set of immunization programs under a budget constraint can be challenging. Recently there have been a number of studies aiming to help policy makers with resource allocation, taking into account multiple criteria such as ethical or political considerations in addition to technical efficiency [62-65].

Note that the results of our financial forecasting and overall disease burden reduction are, of course, sensitive to the forecasted level of demand for rotavirus vaccine. We base our base-case scale-up scenario on local experience with other childhood vaccines and national income levels. However, there are reasons why this forecast may be over- or under-estimated. For instance, there may be discrepancies between reported and actual uptake rates in local settings simply due to the challenges of collecting health information across entire populations. Further, while we assumed that all children covered would receive a full 3 doses of vaccine, in practice dose completion rates may vary, affecting the total cost and altering cost-effectiveness (due to both changes in cost and changes in impact if vaccine efficacy with fewer than 3 doses is lower than that under a full 3-dose course). Thus, to come up with more reliable forecasts for financial requirements associated with new vaccine introduction, more research is needed to improve the quality of coverage data and to conceptualize an approach to forecasting future uptake rate more realistically. Also, some operational research is needed to identify factors that might affect the sustainability of scale-up scenarios.

Our study has several limitations. First, we synthesized available data using an Excel-based model that relies on simplifying assumptions; this was a purposeful tradeoff in that, unlike our past detailed models of a single country [16], here we sought to provide a broad perspective on avertable burden and cost-effectiveness of a global investment to vaccinate children against rotavirus. As such, this simple model cannot capture indirect effects that might result from a large-scale routine immunization program. If a rotavirus program can provide such benefits among non-vaccinated subpopulations, as suggested in recent published studies that used a dynamic mathematical model to estimate the cost-effectiveness of rotavirus vaccines in the United States $[58,66]$, we may be underestimating benefits. Second, unlike our previously published model applied to a single country [16], this static model applied to 72 countries is implicitly based on a decisiontree structure, and thus has a limited capacity to explore uncertainty surrounding natural history of rotavirus infection and potential serotype replacement that might occur in the long term after vaccine introduction $[17,67]$. Third, our analysis assumes composite costs rather than estimating individual country-specific vaccine delivery costs. Accordingly, our results should be carefully interpreted by donors or global policy makers interested in the relative cost-effectiveness of the rotavirus vaccines conditional on alternative strategies to achieve coverage. We emphasize the need for future research to estimate the incremental costs of delivering new rotavirus vaccines in local settings. Lastly, while we tried to estimate countryspecific data for the ratios of hospitalizations and outpatient visits to deaths and for serotype distributions of rotavirus, country-specific data were often not available, leaving us to use data from neighboring countries or regional average.

\section{Conclusion}

The limitations of our study suggest that our findings should be considered for only what they are intendedbroad estimate of the potential impact and value of rotavirus vaccination. Our main findings suggest that rotavirus vaccine introduction would be considered a worthwhile investment for improving general development as well as public health level in most low-income countries, with a favorable cost-effectiveness profile even under a vaccine price (\$1.5-\$5.0 per dose) higher than those of traditional childhood vaccines. In addition, our study provides information on an approximate future stream of financial costs that need to be included in 
health budgets. Further, as more evidence on vaccine efficacy and safety, particularly associated with vaccination schedule in local settings [68], and more country-specific data (e.g., data from the cMYP immunization financing database) become available, our analysis can serve as baseline for any future refinement of country-specific results.

\section{Additional material}

\section{Additional file 1 Supplementary information on model inputs and} results. The document provides detailed information on some of the key model inputs and results, including vaccine efficacy adjusted for serotype distributions, length of stay for rotavirus associated hospitalizations, hourly wage, transportation costs, and country-specific budget impact analysis results.

\section{Competing interests}

The authors declare that they have no competing interests.

\section{Authors' contributions}

SK and SG conceptualized and designed the study. SK and DS acquired data and performed analyses. SK, SS, DS, and SG interpreted the data and results. SK drafted the manuscript. SG provided administrative and technical support, and DS and SS provided technical expertise in managing data quality. All authors contributed to the revision of the manuscript and approved the final version.

\section{Acknowledgements}

SG and SK are funded in part by the Bill and Melinda Gates Foundation for work on HPV vaccines; to the extent the study methodology and decision modeling approach overlaps with our HPV vaccine research, we would like to acknowledge our support from the Foundation. The funding source did not have any influence on the design and conduct of the study. This study is part of a broader set of efforts to inform vaccine policy in low and middle income countries, supported in part by Harvard Initiative for Global Health (Decision Science Working Group). The authors are very grateful to Joshua Chang from the Center for Health Decision Science at Harvard School of Public Health for his technical assistance. We also thank the reviewers for extremely helpful comments during the revision process of the manuscript.

\section{Author Details}

${ }^{1}$ Center for Health Decision Science, Department of Health Policy and Management, Harvard School of Public Health, Boston MA, USA and 2 Harvard Initiative for Global Health, Cambridge, MA, USA

Received: 22 December 2009 Accepted: 14 May 2010

Published: 14 May 2010

\section{References}

1. Kosek M, Bern C, Guerrant RL: The global burden of diarrhoeal disease, as estimated from studies published between 1992 and 2000. Bull World Health Organ 2003, 81(3):197-204.

2. Parashar UD, Hummelman EG, Bresee JS, Miller MA, Glass RI: Global illness and deaths caused by rotavirus disease in children. Emerg Infect Dis 2003, 9(5):565-72.

3. Parashar UD, Burton A, Lanata C, Boschi-Pinto C, Shibuya K, Steele D, Birmingham M, Glass Rl: Global Mortality Associated with Rotavirus Disease among Children in 2004. Journal of Infectious Diseases 2009 , 200(s1):S9-S15.

4. Santos N, Hoshino Y: Global distribution of rotavirus serotypes/ genotypes and its implication for the development and implementation of an effective rotavirus vaccine. Rev Med Virol 2005, 15:29-56.

5. Arista S, Giammanco GM, De Grazia S, Ramirez S, Lo Biundo C, Colomba C, Cascio A, Martella V: Heterogeneity and temporal dynamics of evolution of G1 human rotaviruses in a settled population. J Virol 2006, 80(21):10724-33.
6. Trinh QD, Nguyen TA, Phan TG, Khamrin P, Yan H, Hoang PL, Maneekarn N, Li Y, Yagyu F, Okitsu S, Ushijima H: Sequence analysis of the VP7 gene of human rotavirus $\mathrm{G} 1$ isolated in Japan, China, Thailand, and Vietnam in the context of changing distribution of rotavirus G-types. J Med Virol 2007, 79(7):1009-16.

7. Zahn M, Marshall GS: Clinical and epidemiological aspects of rotavirus infection. Pediatr Ann 2006, 35(1):23-8.

8. WHO: Rotavirus Vaccines. Weekly Epidemiological Record 2007, 82(32):285-296

9. Dennehy PH: Rotavirus vaccines--an update. Vaccine 2007 25(16):3137-41.

10. WHO: Meeting of the immunization Strategic Advisory Group of Experts, April 2009 - conclusions and recommendations. Weekly Epidemiological Record 2009, 84(23):220-236.

11. WHO: Global networks for surveillance of rotavirus gastroenteritis, 2001-2008. Weekly Epidemiological Record 2008, 83(47):421-5.

12. Jamison DT, Breman JG, Measham AR, Alleyne G, Claeson M, Evans DB, Jha $P$, Mills A, Musgrove P: Disease Control Priorities in Developing Countries. 2nd edition. New York: Oxford University Press; 2006.

13. Tan-Torres Edejer T, Baltussen R, Adam T, Hutubessy R, Acharya A, Evans $D B$, Murray CJ: Making choices in health: WHO guide to costeffectiveness analysis. Geneva: World Health Organization; 2003.

14. Drummond MF, Sculpher MJ, Torrance GW, O'Brian BJ, Stoddart GL: Methods for the economic evaluation of health care programmers. New York, NY: Oxford University Press; 2005.

15. WHO: WHO guide for standardization of economic evaluations of immunization programmes. Geneva: World Health Organization; 2008.

16. Kim S, Goldie SJ, Salomon JS: Cost-effectiveness of Rotavirus Vaccination in Vietnam. BMC Public Health 2009, 9:29.

17. Kim SY, Goldie SJ, Salomon JA: Exploring Model Uncertainty in Economic Evaluation of Health Interventions. Society for Medical Decision Making Annual Meeting, Hollywood, CA; 2009.

18. Ruiz-Palacios GM, Perez-Schael I, Velazquez FR, Abate H, Breuer T, Clemens SC, Human Rotavirus Vaccine Study Group, et al:: Safety and efficacy of an attenuated vaccine against severe rotavirus gastroenteritis. NEngl J Med 2006, 354(1):11-22.

19. Murray CJL, Lopez AD: The Global Burden of Disease, Vol. 1 of Global Burden of Disease and Injury Series. Cambridge, MA: Harvard University Press; 1996

20. Mathers CD, Salomon JA, Ezzati M, Begg S, Hoorn SV, Lopez AD: Sensitivity an uncertainty analyses for burden of disease and risk factor estimates. In Global Burden of Disease and Risk Factors Edited by: Lopez AD, Mathers CD, Ezzati M, Jamison DT, Murray CJL. Washington: Oxford University Press; 2006:399-426.

21. GAVI Alliance: Candidate Rotavirus Vaccine Recommendations for Consideration by the WHO Strategic Advisory Group of Experts (SAGE) on Immunization Geneva; 2009.

22. WHO: World Health Statistics WHO, Geneva; 2008.

23. Nations United Department of Economic and Social Affairs Division Population: World Population Prospects: The 2006 Revision. CD-ROM Edition - Extended Dataset in Excel and ASCII formats (United Nations publication, Sales No. E.07.XIII.7) 2007.

24. WHO: Life tables for WHO member states: 2006. [http://www.who.int/ whosis/database/life tables/life tables.cfm]

25. Flem ET, Latipov R, Nurmatov ZS, Xue Y, Kasymbekova KT, Rheingans RD: Costs of diarrheal disease and the cost-effectiveness of a rotavirus vaccination program in kyrgyzstan. J Infect Dis 2009, 200(Suppl 1):S195-202.

26. Rheingans RD, Constenla D, Antil L, Innis BL, Breuer T: Potential costeffectiveness of vaccination for rotavirus gastroenteritis in eight Latin American and Caribbean countries. Rev Panam Salud Publica 2007 21(4):205-216

27. Arvay ML, Curns AT, Terp S, Armah G, Wontuo P, Parashar UD, Binka F, Glass RI, Widdowson MA: How much could rotavirus vaccines reduce diarrhea-associated mortality in northern Ghana? A model to assess impact. J Infect Dis 2009, 200(Suppl 1):S85-S91.

28. Benhafid M, Youbi M, Klena JD, Gentsch JR, Teleb N, Widdowson MA Epidemiology of rotavirus gastroenteritis among children $<5$ years of age in Morocco during 1 year of sentinel hospital surveillance, June 2006-May 2007. J Infect Dis 2009, 200:S70-5. 
29. WHO: Estimated rotavirus deaths for children under 5 years of age: 2004. [http://www.who.int/immunization monitoring/burden/ rotavirus estimates/en/index.html].

30. International Labour Office: Database on labour statistics (LABORSTA). [http://laborsta.ilo.org/]

31. Bank World: World Development Indicators Online. [http:// web.worldbank.org/WBSITE/EXTERNAL/DATASTATISTICS/ 0,contentMDK:20398986 pagePK:64133150 piPK:64133175 theSitePK: 239419,00.html].

32. GAVI Alliance: Policy Brief: GAVI Alliance New Vaccine Co-financing Policy. Geneva; 2009.

33. Linhares AC, Velázquez FR, Pérez-Schael I, Sáez-Llorens $X$, Abate H, Espinoza F, López P, Macías-Parra M, Ortega-Barría E, Rivera-Medina DM, Rivera L, Pavía-Ruz N, Nuñez E, Damaso S, Ruiz-Palacios GM, De Vos B, O'Ryan M, Gillard P: Efficacy and safety of an oral live attenuated human rotavirus vaccine against rotavirus gastroenteritis during the first 2 years of life in Latin American infants: a randomised, double-blind, placebo-controlled phase III study. Lancet 2008, 371(9619):1181-9.

34. Mauskopf JA, Sullivan SD, Annemans L, Caro J, Mullins CD, Nuijten M, Orlewska E, Watkins J, Trueman P: Principles of good practice for budget impact analysis: Report of the ISPOR task force on good research practices-Budget impact analysis. Value in Health 2007, 10(5):336-47.

35. Marshall DA, Douglas PR, Drummond MF, Torrance GW, MacLeod S, Manti O, Cheruvu L, Corvari R: Guidelines for conducting pharmaceutical budget impact analyses for submission to public drug plans in Canada. Pharmacoeconomics 2008, 26(6):477-95.

36. Atherly D, Dreibelbis R, Parashar UD, Levin C, Wecker J, Rheingans RD: Rotavirus vaccination: cost-effectiveness and impact on child mortality in developing countries. J Infect Dis 2009, 200(Suppl 1):S28-38.

37. Wolfson L, Gasse F, Lee-martin S, Lydon P, Magan A, Tibouti A, Johns B, Hutubessy R, Salama P, Okwo-Bele JM: Estimating the Costs of Achieving the WHO-UNICEF Global Immunization Vision and Strategy, 20062015. Bulletin of the World Health Organization 2008, 86(1):27-39.

38. WHO: The World Health Report 2002: Reducing Risks, Promoting Healthy Life. WHO, Geneva; 2002.

39. Rose J, Hawthorn RL, Watts B, Singer ME: Public health impact and cost effectiveness of mass vaccination with live attenuated human rotavirus vaccine (RIX4414) in India: model based analysis. BMJ 2009, 339:b3653.

40. Fischer TK, Anh DD, Antil L, Cat ND, Kilgore PE, Thiem VD, Rheingans $R$, Tho le H, Glass Rl, Bresee JS: Health care costs of diarrheal disease and estimates of the cost-effectiveness of rotavirus vaccination in Vietnam. $J$ Infect Dis 2005, 192(10):1720-6.

41. Podewils LJ, Antil L, Hummelman E, Bresee J, Parashar UD, Rheingans R: Projected cost-effectiveness of rotavirus vaccination for children in Asia. J Infect Dis 2005, 192(Suppl 1):S133-45.

42. Isakbaeva ET, Musabaev E, Antil L, Rheingans R, Juraev R, Glass RI, Bresee $J S$ : Rotavirus disease in Uzbekistan: Cost-effectiveness of a new vaccine. Vaccine 2007, 25:373-380

43. Tate JE, Rheingans RD, O'Reilly CE, Obonyo B, Burton DC, Tornheim JA, Adazu K, Jaron P, Ochieng B, Kerin T, Calhoun L, Hamel M, Laserson K, Breiman RF, Feikin DR, Mintz ED, Widdowson MA: Rotavirus disease burden and impact and cost-effectiveness of a rotavirus vaccination program in kenya. J Infect Dis 2009, 200(Suppl 1):S76-84.

44. Flem ET, Musabaev E, Juraev R, Kerin T, Gentsch J, Glass RI, Bresee JS: Rotavirus gastroenteritis in uzbekistan: implications for vaccine policy in central Asia. J Infect Dis 2009, 200(Suppl 1):S114-24.

45. Clark AD, Walker DG, Mosqueira NR, Penny ME, Lanata CF, Fox-Rushby J, Sanderson CF: Cost-effectiveness of rotavirus vaccination in peru. $J$ Infect Dis 2009, 200(Suppl 1):S114-24.

46. Ortega O, El-Sayed N, Sanders JW, Abd-Rabou Z, Antil L, Bresee J, Mansour A, Adib I, Nahkla I, Riddle MS: Cost-benefit analysis of a rotavirus immunization program in the Arab Republic of Egypt. J Infect Dis 2009, 200(Suppl 1):S92-8.

47. Wang XY, Riewpaiboon A, von Seidlein L, Chen XB, Kilgore PE, Ma JC, Qi $S X$, Zhang ZY, Hao ZY, Chen JC, Xu ZY: Potential cost-effectiveness of a rotavirus immunization program in rural China. Clin Infect Dis 2009, 49(8):1202-10.

48. Soarez PC, Valentim J, Sartori AMC, Novaes HMD: Cost-effectiveness análisis of routine rotavirus vaccination in Brazil. Rev Panam Salud Publica 2008, 23(4):221-230.
49. Valencia-Mendoza A, Bertozzi SM, Gutierrez JP, Itzler R: Cost-effectiveness of introducing a rotavirus vaccine in developing countries: The case of Mexico. BMC Infectious Diseases 2008, 8:103.

50. Constenla DO, Linhares AC, Rheingans RD, Antil LR, Waldman EA, da Silva LJ: Economic Impact of a Rotavirus Vaccine in Brazil. J HEALTH POPUL NUTR 2008, 26(4):388-396.

51. Constenla D, Velázquez FR, Rheingans RD, Antil L, Cervantes Y: Economic impact of a rotavirus vaccination program in Mexico. Rev Panam Salud Publica 2009, 25(6):481-90.

52. Rheingans RD, Antil L, Dreibelbis R, Podewils LJ, Bresee JS, Parashar UD: Economic Costs of Rotavirus Gastroenteritis and Cost-Effectiveness of Vaccination in Developing Countries. Journal of Infectious Diseases 2009, 200:S16-27.

53. Jit M, Edmunds WJ: Evaluating rotavirus vaccination in England and Wales: Part II. The potential cost-effectiveness of vaccination. Vaccine 2007, 25:3971-3979

54. Lorgelly PK, Joshi D, Iturriza Gómara M, Gray J, Mugford M: Exploring the cost effectiveness of an immunization programme for rotavirus gastroenteritis in the United Kingdom. Epidemiol Infect 2008, 136(1):1-12.

55. Widdowson MA: Cost-effectiveness and Potential Impact of Rotavirus Vaccination in the United States. Pediatrics 2007, 119(4):684-697.

56. Melliez H, Levybruhl D, Boelle PY, Dervaux B, Baron S, Yazdanpanah Y: Cost and cost-effectiveness of childhood vaccination against rotavirus in France. Vaccine 2008, 26(5):706-15.

57. Newall AT, Beutels P, Macartney K, Wood J, Maclntyre CR: The costeffectiveness of rotavirus vaccination in Australia. Vaccine 2007, 25(52):8851-60

58. Shim E, Galvani AP: Impact of transmission dynamics on the costeffectiveness of rotavirus vaccination. Vaccine 2009, 27(30):4025-30.

59. Jit M, Bilcke J, Mangen MJ, Salo H, Melliez H, Edmunds WJ, Yazdan $Y$, Beutels P: The cost-effectiveness of rotavirus vaccination: Comparative analyses for five European countries and transferability in Europe. Vaccine 2009, 27(44):6121-8.

60. Goldie SJ, O'Shea M, Campos NG, Diaz M, Sweet S, Kim S: Health and economic outcomes of HPV 16,18 Vaccination in 72 GAVI-eligible countries. Vaccine 2008, 26(32):4080-93.

61. Ferlay J, Bray F, Pisani P, Parkin DM: GLOBOCAN 2002. Cancer Incidence, Mortality and Prevalence Worldwide. In IARC Cancer Base No. 5 Version 2.0 Lyon, France: IARCPress; 2004

62. Jehu-Appiah C, Baltussen R, Acquah C, Aikins M, d'Almeida SA, Bosu WK Koolman X, Lauer J, Osei D, Adjei S: Balancing equity and efficiency in health priorities in Ghana: the use of multicriteria decision analysis. Value in Health 2008, 11:1081-87.

63. Baltussen R, Niessen L: Priority setting of health interventions: the need for multi-criteria decision analysis. Cost Effectiveness and Resource Allocation 2006, 4(14):

64. Baltussen R, Asbroek AHA, Koolman X, Shrestha N, Bhattarai P, Niessen LW: Priority Setting using multiple criteria: should a lung health programme be implemented in Nepal? Health Policy and Planning 2007, 22:178-185

65. Epstein DM, Chalabi Z, Claxton K, Sculpher M: Efficiency, Equity, and Budgetary Policies: Informing Decisions Using Mathematical Programming. Medical Decision Making 2007, 27:128-137.

66. Pitzer VE, Viboud C, Simonsen L, Steiner C, Panozzo CA, Alonso WJ, Miller MA, Glass RI, Glasser JW, Parashar UD, Grenfell BT: Demographic Variability, Vaccination, and the Spatiotemporal Dynamics of Rotavirus Epidemics. Science 2009, 35(5938):290-294.

67. Kim S, Goldie SJ: Cost-effectiveness analyses of vaccination programmes: a focused review of modelling approaches. Pharmacoeconomics 2008, 26(3):191-215.

68. Danchin MH, Bines JE: Defeating Rotavirus? The Global Recommendation for Rotavirus Vaccination. N Eng/ J Med 2009, 361(20):1919-1921.

Pre-publication history

The pre-publication history for this paper can be accessed here: http://www.biomedcentral.com/1471-2458/10/253/prepub

doi: $10.1186 / 1471-2458-10-253$

Cite this article as: Kim et al., Health and economic impact of rotavirus vaccination in GAVI-eligible countries BMC Public Health 2010, 10:253 